Université de Montréal

\title{
Stakeholders' Conceptualizations of the Nurse \\ Practitioner Role in the Pediatric Emergency Department
}

\author{
par \\ Louise Murray, inf. B.Sc. \\ Faculté des Sciences Infirmières
}

Mémoire présenté à la Faculté des études supérieures

en vue de l'obtention du grade de Maître ès sciences (M.Sc.)

en sciences infirmières

5 janvier 2007

(C) Louise Murray, 2007

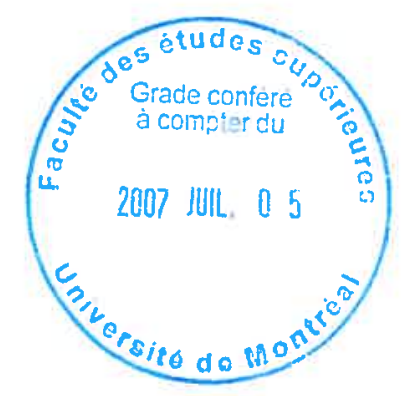


WY

5

458

2007

V.012 
Direction des bibliothèques

\section{AVIS}

L'auteur a autorisé l'Université de Montréal à reproduire et diffuser, en totalité ou en partie, par quelque moyen que ce soit et sur quelque support que ce soit, et exclusivement à des fins non lucratives d'enseignement et de recherche, des copies de ce mémoire ou de cette thèse.

L'auteur et les coauteurs le cas échéant conservent la propriété du droit d'auteur et des droits moraux qui protègent ce document. Ni la thèse ou le mémoire, ni des extraits substantiels de ce document, ne doivent être imprimés ou autrement reproduits sans l'autorisation de l'auteur.

Afin de se conformer à la Loi canadienne sur la protection des renseignements personnels, quelques formulaires secondaires, coordonnées ou signatures intégrées au texte ont pu être enlevés de ce document. Bien que cela ait pu affecter la pagination, il n'y a aucun contenu manquant.

\section{NOTICE}

The author of this thesis or dissertation has granted a nonexclusive license allowing Universite de Montreal to reproduce and publish the document, in part or in whole, and in any format, solely for noncommercial educational and research purposes.

The author and co-authors if applicable retain copyright ownership and moral rights in this document. Neither the whole thesis or dissertation, nor substantial extracts from it, may be printed or otherwise reproduced without the author's permission.

In compliance with the Canadian Privacy Act some supporting forms, contact information or signatures may have been removed from the document. While this may affect the document page count, it does not represent any loss of content from the document. 
Université de Montréal

Faculté des études supérieures

Ce mémoire intitulé :

\section{Stakeholders' Conceptualizations of the Nurse \\ Practitioner Role in the Pediatric Emergency Department}

présenté par:
Louise Murray, inf, B.Sc.

a été évalué par un jury composé des personnes suivantes :

Mary McQueen Reidy, PhD- Directrice

Franco Carnevale, PhD- Co-directeur

Danielle D'Amour, PhD- Présidente du jury

Jane Chambers- Evans - Membre du jury 


\section{SOMMAIRE}

Au Québec comme aux E.-U. et au R.-U., les services d'urgence (SU) voient de plus en plus le volume de leurs patients augmenter, en même temps que la complexité et la gravité des cas s'accentue et que l'on dispose de moins en moins de lits pour les soins de courte durée. Cette demande accrue de services, à laquelle s'ajoute un nombre toujours décroissant de médecins, d'infirmières et de stagiaires (médicaux ou en sciences infirmières), a obligé les gestionnaires de SU à se poser la question à savoir s'il ne faudrait pas ajouter de nouveaux types d'intervenants. Parallèlement, il est possible que le rôle d'infirmière praticienne (IP) soit bientôt intégré aux services d'urgence des hôpitaux du Québec, puisqu'une nouvelle loi permet maintenant son introduction.

Certains théoriciens considèrent que le développement d'un nouveau rôle (comme celui de I'IP aux services d'urgence) s'inscrit dans un processus dynamique de partage des attentes et des conceptions dans le but d'assurer la stabilité des interactions. If est donc hautement pertinent d'examiner les attentes et les conceptions de ceux qui sont les plus concernés, c'est-à-dire les parties prenantes.

Compte tenu de la pertinence de ce phénomène et de la rareté de la documentation canadienne sur le sujet, nous avons mené une étude en employant une méthode exploratoire qualitative, dont les objectifs étaient les suivants : déterminer les conceptions et les attentes des parties prenantes quant au rôle de l'infirmière praticienne aux services d'urgence pédiatrique (à ses premiers stades de développement), savoir si ces conceptions correspondaient à leurs attentes, et déterminer les facteurs d'influence de ces conceptions. 
Onze parties prenantes ont été sélectionnées et rencontrées en entrevue. Les données ont été analysées par rapport à leur contenu. Les résultats confirment l'opinion selon laquelle les parties prenantes se sont déjà fait une idée du rôle comme tel, de même que du processus de développement du rôle, et que ces conceptions guident leurs attentes, tant par rapport au rôle que par rapport au processus de développement du rôle. Les parties prenantes insistent tout particulièrement sur l'importante d'établir clairement en quoi consiste ce rôle, si on veut assurer son succès et son acceptation, car ce rôle changera la façon dont les médecins, les infirmières et les stagiaires (en médecine ou en sciences infirmières) exerceront leur pratique. Toutes les parties prenantes s'attendent à ce qu'une équipe formée de certaines d'entre elles détenant des postes clés soit impliquée dans le processus de développement de ce rôle d'infirmière. Elles considèrent ce rôle comme un rôle de collaboration qui permettra de faire le pont entre les diverses tâches accomplies actuellement par les infirmières, les stagiaires et les médecins. Elles s'attendent à ce que ce rôle soit intégré progressivement sous certaines conditions précises. Les conclusions de cette étude permettra de mieux comprendre le développement du rôle.

\section{Mots Clés}

pratique infirmière avancée, infirmière praticienne aux services d'urgence, parties prenantes, rôles, développement de rôle 


\section{SUMMARY}

In Quebec, as in the US and UK, hospital Emergency departments (EDs) have seen a significant increase in patient volumes, rising acuity and complexity of care and reduced access to acute care beds. This increased demand for service, coupled with dwindling resources of physicians, nurses and nursing and medical trainees has obliged those managing EDs to question if new roles need to be introduced. Simultaneously, the nurse practitioner (NP) role may be operationalized in Quebec EDs in the near future, as new legislation has cleared the path for its introduction.

Some theorists view the development of a new role (such as the Emergency NP) as a dynamic process of shared expectations and conceptions (conceptualizations) used to maintain stable interaction. It is therefore very relevant to study the conceptualizations of those most closely involved, the stakeholders.

Considering the pertinence of this phenomenon, and the lack of Canadian literature on the subject, a qualitative exploratory method was employed to identify stakeholders' conceptualizations of the pediatric emergency nurse practitioner role (during the early stages of its development), how these conceptions are related to their expectations, and the factors which influence these conceptualizations. Eleven stakeholders were recruited and interviewed. Data were content analyzed. The results support the view that stakeholders already have conceptualizations of the role itself, as well as the role development process, and that these conceptions guide their expectations of both the role and the role development process. Stakeholders emphasize that 
role clarity is crucial for its success and acceptance, as it will modify how physicians, nurses and nursing and medical trainees will function in the future. All stakeholders have expectations that a team of key stakeholders should be involved in the development process of this nursing role. They view this role as a collaborative one that will bridge the gap between what nurses, trainees and physicians currently do. They have expectations of this role being implemented progressively under certain specific conditions. These findings have enhanced our understanding of role development in pediatric EDs, which may be relevant for other settings as well.

\section{Key words}

Advanced nursing practice, emergency nurse practitioner, stakeholders, roles, role development 


\section{TABLE OF CONTENTS}

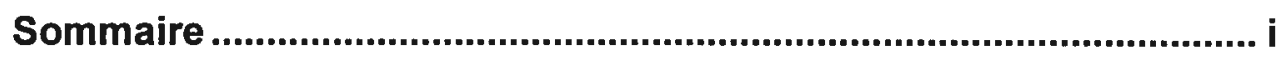

Summary .............................................................................................. iii

Acknowledgements .............................................................................. xiii

CHAPTER 1 - THE RESEARCH PROBLEM ..................................... 1

1 The Research Problem .......................................................... 2

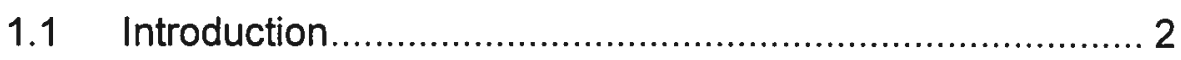

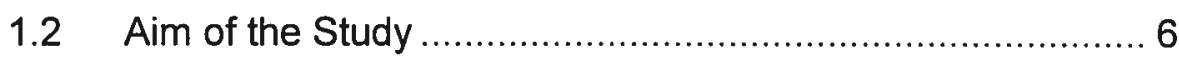

1.3 Research Questions ........................................................... 7

CHAPTER 2 - REVIEW OF THE LITERATURE ................................ 8

2 Review of the Literature ........................................................ 9

2.1 Role Theory and Development of Advanced .................... 9

Nursing Practice

2.2 Development of Advanced Nursing Practice .................... 12

2.3 Research and Clinical Descriptions of the ....................... 17

Emergency Nurse Practitioner Role and Its Evolution

2.3.1 Role Evolution................................................... 17

2.3.2 Research Descriptions of Emergency .................. 20

Nurse Practitioner Role

2.3.3 Clinical Descriptions of the Emergency................. 25

Nurse Practitioner Role

2.4 Legal Aspects that Govern the Clinical Context for NPs... 29

2.4.1 Position Statements of Various ............................. 33

Governing Bodies

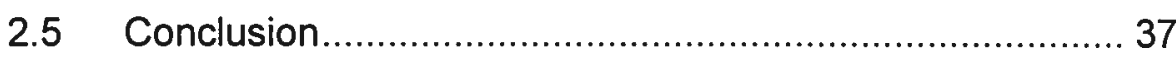




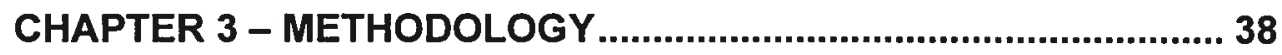

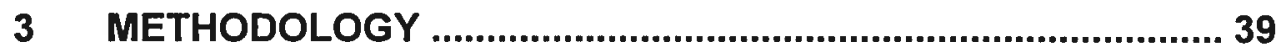

3.1 Site and Participant Selection ........................................... 39

3.2 Data Collection Process ................................................... 43

3.3 Development of the Interview Guide................................. 43

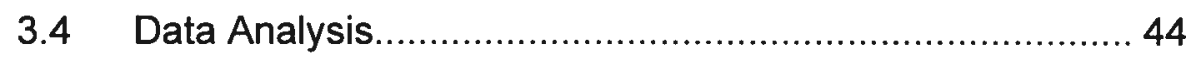

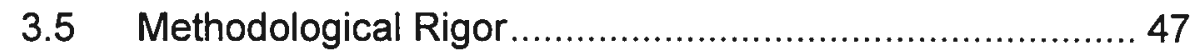

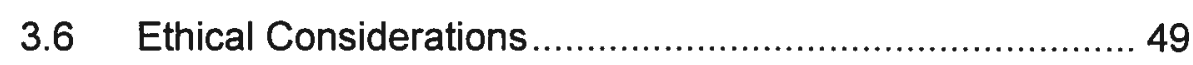

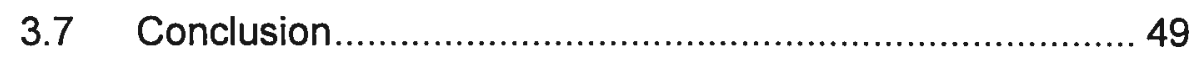

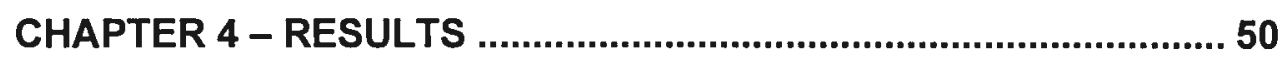

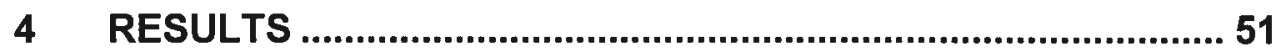

4.1 Conceptualizations of the Emergency Nurse ..................... 51

Practitioner Role: Questioning of the Medical and

Nursing Dimensions of the Emergency Nurse

Practitioner Role

4.1.1 Extend Nursing Role at Triage ............................ 54

4.1.1.1 Clinical role for selected fast track ............... 54 patients with clear diagnosis

4.1.1.2 Teach, mentor nurses, ................................ 55 trainees and patients

4.1.1.3 Limit administrative role.............................. 56

4.1.1.4 Limit research responsibilities ...................... 56

4.1.1.5 Provide follow-up for specific populations.... 57

4.1.2 Bridge Gaps Between Nursing ........................... 58 and Physician Roles

4.1.2.1 Initiate treatment for physician after triage ... 59 for selected populations using protocols

4.1.2.2 Perform advanced procedures/deliver ......... 59 complex care using protocols 
4.1.2.3 Work as part of a team ............................6 60

4.1.3 Limit NP to Specific Populations ........................ 61

4.1.3.1 Not be involved in critical care/consults....... 62

4.1.3.2 Determine independence, autonomy .......... 63 and ultimate responsibility for patient

4.1.3.3 Clarify NP responsibilities......................... 64

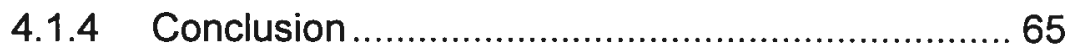

4.2 Conceptualizations of the Role Development Process: .... 66 Recognizing the Role Development Process

4.2.1 View as a New Role/Redefine Other 69 Nurses' Roles

4.2.1.1 Determine stakeholder role expectations/... 70 limit input from governing bodies

4.2.1.2 Educational requirements......................... 71

4.2.1.3 Consider special challenges .................... 72 for the first candidates

4.2.1.4 Build new role on competencies/................ 73 consider needs, limitations

4.2.2 Attend to Group Process.................................. 74

4.2.3 Enlist Support from ER Stakeholders ................ 76 and Hospital Administrators

4.2.4 Ensure Candidates are Autonomous Clinical ...... 77 Experts with Strong Inter-Personal Skills

4.2.5 Recognize this Role Will Change the Current ..... 78 Nurse/ Physician Dynamics

4.2.5.1 Consider impact on nurses....................... 79

4.2.5.2 Consider impact on physicians.................. 80

4.2.5.3 Consider evolution of role over time ........... 81

4.2.6 Anticipate Potential Benefits to Patients ............. 82

4.2.7 Conclusion ................................................. 83 
4.3 ER Contextual Considerations and the Larger Legal ....... 84 Context: Organizational Barriers and Facilitators

4.3.1 Consider Potential Barriers .............................. 86

4.3.1.1 Consider unpredictable environment with.... 87 high patient volumes and rapid turnover

4.3.1.2 Consider financial resources ..................... 88

4.3.1.3 Consider the impact of large numbers ........ 88 of staff and turnover

4.3.1.4 Consider the need for role longevity........... 89

4.3.1.5 Consider the OIIQ, the collège des ............ 90 médecins, and other governing bodies

4.3.2 Consider Facilitating Factors ............................ 91

4.3.2.1 Consider MCH history in NP development ... 92

4.3.2.2 Consider parents' reaction to change........... 93

4.3.2.3 Consider the NP role as an addition ........... 94 to current human resources

4.3.3 Consider Quebec's Evolving Legal Context......... 95

4.3.3.1 Determine levels of responsibility and ........ 96 accountability of the NP within an unclear legal context

4.3.3.2 Unfamiliar with position statements ............ 97

4.4 Conclusion.......................................................... 98

4.5 Critical Synthesis of the Results ............................... 99

CHAPTER 5 - DISCUSSION ....................................................... 105

5 DISCUSSION....................................................................... 106

5.1 Pertinence and Contribution to Nursing Knowledge ....... 106

5.2 Conceptualizations of the NP Role ............................ 108

5.3 Conceptualizations of the NP Role ............................ 111 Development Process 
5.3.1 Role Ambiguity....................................... 112

5.3.2 Role Incongruity ...................................... 114

5.3.3 Role Conflict .............................................. 115

5.3.4 ER Contextual Considerations and the Larger ... 116 Legal Context: Organizational Barriers and Facilitators

5.4 Strengths and Limitations of the Study ..................... 119

5.5 Recommendations for Research and Nursing Practice... 121

5.5.1 Recommendations for Research .................... 121

5.5.2 Recommendations for Nursing Practice............ 122

5.6 Conclusion........................................................ 123

REFERENCES .................................................................... 125

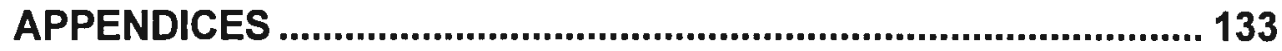

APPENDIX A ........................................................................ 134

Interview Guide ......................................................... 134

Research and Clinical Descriptions the Role ............... 134

of Emergency Nurse Practitioners and Its Evolution

in Other Settings

Role Development................................................. 135

The Context........................................................ 135

Position Statements and Legal Aspects Which ........... 136

Govern the Clinical Context for NPs

Demographic Data................................................ 136 


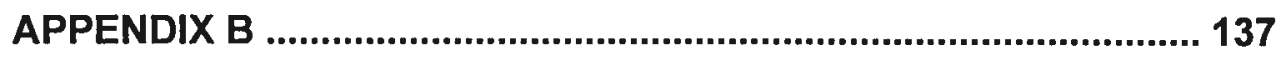

Request for Your Participation in a Research Project ............... 137

Title of the Study........................................................ 138

Duration of Data Collection............................................. 138

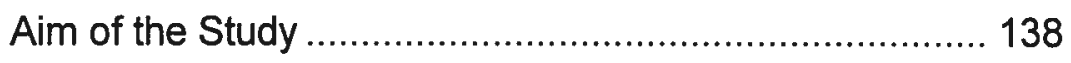

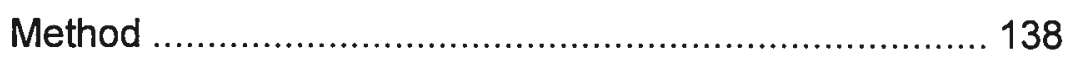

Risk for Participants and Control Measures ................... 139

Scientific Merit/Social Value ........................................... 139

Consent Form for Participants ............................................... 140

Title of the Study......................................................... 140

Date/duration of Data Collection..................................... 140

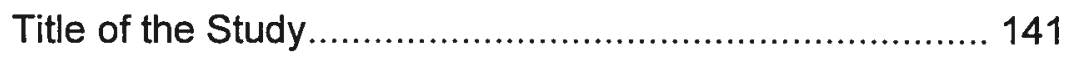

Date/Duration of Data Collection ..................................... 141

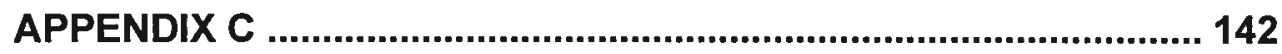

Data Category Analyses: Divergence and Convergence ......... 142

of Categories Among Participants 


\section{LIST OF TABLES}

Table I Participant Demographic Data.......................................... 42

Table II Conceptions and Expectations of NP role .................... 142

Table III Conceptions and Expectations of role development process ............................................. 143

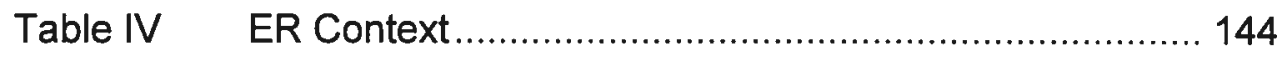

Table V Legal context/Position statements ................................ 144 


\section{LIST OF FIGURES}

Figure 1 Stakeholder Conceptions IExpectations of NP role .......... 53

Figure 2 Conceptualizations of role development process ............ 68

Figure 3 ER contextual considerations ILegal context................... 85 


\section{ACKNOWLEDGEMENTS}

This project was made possible because a number of people believed in me, and in my abilities.

I would like to begin by thanking my supervisor, Dr Mary Reidy, N, PhD, for her guidance, expertise and patience. This project evolved over a number of years, and I am grateful for your ongoing support.

I am also very grateful for the guidance of my co-supervisor Dr Franco Carnevale, N, PhD. Your mentorship over the years and especially throughout this project has been invaluable. You have greatly contributed to the development of advanced practice nursing in the hospital setting; this project is another concrete example of this. Thank you.

I would also like to thank the stakeholders who agreed to participate in this study. Thank-you for sharing your expertise.

To the groups who provided financial assistance for this project in the form of bursaries, your financial support is very appreciated and contributed to making this possible. I especially wish to acknowledge the financial support provided by Centre FERASI.

Finally, I would like to especially acknowledge the support of my family and friends. To my husband Jean-François, who provided support in so many ways and made it possible to achieve this goal. To my daughter Catherine, who has been so patient while anxiously awaiting the end of this project for so many years. To my son John Michael, who has been 
so generous in letting 'mommy run off to study'. To my parents and siblings who supported me in a number of important ways, especially during the difficult periods. To my friend Akoulina, thank you for sharing your expertise and talents. Your help was invaluable in editing this document. I could not have done this without you, and I am grateful to you all. Thank you for being there for me. 


\section{CHAPTER 1}

THE RESEARCH PROBLEM 


\section{THE RESEARCH PROBLEM}

\subsection{Introduction}

As in the United States (US), the United Kingdom (UK), and the rest of Canada, over the past several years Québec hospital Emergency departments (EDs) have seen a significant increase in patient volumes, reduction in medical and nursing personnel, reduced access to acute care beds (Gouvernement du Québec, 1999), and rising acuity and complexity of care. Overcrowding coupled with a decreased number of medical staff, nursing staff and trainees has obliged those concerned with functioning EDs to question the traditional roles of nurses and physicians as well as the need for new roles in the treatment of ED patients. Concurrently, the Nurse Practitioner (NP) role is being operationalized in Quebec, as new legislation has cleared the path for its introduction.

In the US, pressures contributing to the emergence of the NP role stemmed from lack of access to physicians for some segments of the population and the movement toward a more active role for nurses in health care. In the UK, major factors included decreasing numbers of junior medical staff, increasing numbers of ED patients, policy reports encouraging the use of emergency nurse practitioners to decrease wait times and improve care quality, and changes to scope of practice (Hamric, Spross \& Hanson, 1996; Tye \& Ross, 1997). In both the US and UK, support for expanded roles for nurses, in addition to the aforementioned pressures, led to the development of the NP role. 
Current literature from both countries is rich with post-implementation descriptions of the role of the emergency nurse practitioner role (Cole \& Ramirez, 1999; Kemp, 1998; Robertson, 1999; Sanning Shea \& SelfridgeThomas, 1997). Further, a number of authors describe factors they believe favor and inhibit the advanced practice role in general (Patterson and Haddad, 1992; Rubin, 1988; Van der Horst and Patterson, 1993). However, few studies examine the factors favoring the development of new advanced practice roles within the pediatric emergency context; (Hamric et al, 1996; Woods, 1999), and none have come to light which demonstrate the conceptualizations (i.e., conceptions and expectations) of those most involved (stakeholders) in the planning stage of this multiphase process in pediatric ED settings.

Although the NP role is somewhat defined by the legal context of each individual province (or state), the pediatric ER has different needs, conceptions and expectations of the role in question. Since pediatric EDs differ from other settings, the development of the new emergency nurse practitioner role raises many questions. It is important to explore and identify these before the role is developed and implemented, as this data will prove salient to those with future involvement.

The prominence of role descriptions and emphasis placed on defining the emergency nurse practitioner role in the current US and UK literature illustrates the importance of concentrating on role development. The notion of role is key, and literature on NPs continues to proliferate, with much of it focusing on issues pertinent to role definition and justification (Knafl, 1978). However, no descriptions were discovered in any of this literature on how these roles were developed. 
Traditionally, role development has been considered an interactive process, whereby an actor conformed to the expectations, values and morally sanctioned patterns shared by the group in which the role functioned. While role behavior is traditionally viewed as a consequence of actors following culturally given or situationally negotiated rules, Hilbert (1981; page 216) argues that role is better viewed as "an organizing concept of shared expectations and conceptions used to maintain the stability of the social interaction". In times of rapid organizational change and uncertainty, roles are no longer strictly defined, but more likely to be developed by stakeholders, i.e., one who has a share or an interest in an enterprise (American Heritage Dictionary of the English Language, 2000).

Hamric, et al (1996) studied the development of the Clinical Nurse Specialist (CNS) role, and developed a model describing four major phases of role development. Among strategies offered to enhance APN role implementation at work during the first development phase (i.e., orientation), the authors cite the importance of establishing mutually agreed upon role expectations, meeting with key players and peer networking. Administrative factors found to enhance the effectiveness of this advanced practice role include a good fit between the goals and expectations of the individual and those of the organization (Hamric, et al, 1996; Rubin, 1988). It is clear that the organization plays an important role in determining the success or failure of newly developed advanced practice roles, and that stakeholder perception is essential to success.

L'Ordre des infirmières et infirmiers du Québec (OIIQ, 2001) recommends modifications to the laws governing nursing practice in our province. Specifically, they recommend that scope of practice for nurses 
be enlarged to allow nurses to maintain practice adapted to the profound changes transforming the Quebec health system. The Act to amend the Professional Code and other legislative provisions regarding the health sector came into effect in January 2003, expanding the scope of practice guidelines for nurses, and introducing the role of Nurse Practitioner (Infirmière Praticienne Spécialisée). This change in legislation opens the door to the development of the emergency nurse practitioner role in Quebec EDs.

Little is known about the conceptualizations (i.e., conceptions and expectations) of stakeholders in nursing administration, the hospital administration, staff nurses and physicians of pediatric ED setting in Quebec, in relation to the emergency nurse practitioner role. Before implementing such a role, input from these multidisciplinary stakeholders is imperative to facilitating the development of an effective role within the organization. Issues such as professional and legal implications, educational aspects, cost effectiveness, emergency nurse practitioner consultation styles and future developments must be considered and discussed extensively before the role can be effectively designed and implemented (Tye, 2000).

Stakeholder viewpoint is important for several reasons. It may elucidate current needs, priorities and strengths as perceived by those most involved. In this context, an advanced practice role can then be successfully developed, helping construct the role based on current strengths perceived by the group. As co-participants in the role development process, such input may become a catalyst to successful development. Further, the stakeholders' conceptualizations (i.e., conceptions and expectations) of the role will influence the design 
and evolution of the role at least until it is operationalized in the pediatric ER context.

There is little or no empirical data available in Quebec or Canada to reliably inform future developments. At present, there is a paucity of Canadian literature regarding the description of the nurse practitioner role in the ED. There is, however, support for advanced nursing practice roles in both Quebec and Canada. The Canadian Nurses Association (CNA, 2000) specifies the necessity to develop roles reflecting the needs of the unique Canadian health care system, including activities traditionally considered outside the scope of nursing practice.

Considering the lack of Canadian literature on this subject, absence of such roles in Quebec hospital EDs, the importance of role development using stakeholder views, scarcity of data on how these roles are determined or defined, and recent changes in legislation, this study examines stakeholder views of the emergency nurse practitioner role in the pediatric ED. To enhance understanding of emerging conceptualizations (i.e., conceptions and expectations) of the emergency nurse practitioner role during the early planning stage, an exploratory descriptive qualitative method has been selected. Miles \& Huberman (1994) emphasize that qualitative data are a source of wellgrounded, rich descriptions and explanations of processes in identifiable local contexts.

\subsection{Aim of the Study}

The aim of the study is to identify stakeholders' conceptualizations (i.e., conceptions and expectations) in the planning stage of the pediatric emergency nurse practitioner role. 


\subsection{Research Questions}

Research questions evolving from this aim are as follows:

- What are the emerging conceptualizations (i.e., conceptions and expectations) of the major stakeholders of a pediatric Emergency department of the emergency nurse practitioner role, in the planning phase of role development?

- What are the emerging conceptualizations (i.e., conceptions and expectations) of the major stakeholders of a pediatric Emergency department of the role development process?

- What factors influence these conceptualizations of the nurse practitioner role in this pediatric emergency department setting? 


\begin{tabular}{c}
\hline CHAPTER 2 \\
REVIEW OF THE \\
LITERATURE \\
\hline
\end{tabular}




\section{REVIEW OF THE LITERATURE}

In keeping with qualitative research methods, the researcher used scientific literature to better understand the phenomenon under study. The laws governing nursing practice in Quebec, as well as the needs of individual clinical contexts in part define this advanced practice role. Four themes, relevant to the phenomenon under study have been selected from the literature to enhance comprehension of the development of the nurse practitioner role in the pediatric ED: role theory and development of advanced nursing practice; research and clinical descriptions of the emergency nurse practitioner role and its evolution; legal aspects which govern the clinical context for NPs; and position statements from various organizations which serve as guidelines for emergency nurse practitioner practice. This chapter presents a review and critical synthesis of these themes.

\subsection{Role Theory and Development of Advanced Nursing Practice}

Role theory "refers to a collection of concepts and a variety of theoretical formulations that predict how actors will perform in a given role" (Hardy and Conway, 1978; page 17). Hilbert's (1981) interpretation of the classic sociological works of Parsons, Linton (who expressed the functionalist position of role theory), and finally Turner (who expressed the interactionist position of role theory), is outlined in this section.

Role, through the eyes of sociologist Parson's classic views on sociology, whose theoretical objective is the explanation of observed social order, identifies the problem of accounting for organized human 
activity. The term role emerged in the sociological literature with Linton, who explains the functionalist point of view of role development as being governed by rules; rule behaviour is a consequence of adhering to those rules.

Turner, from an interactionist viewpoint, proposes that actors actively create their roles as they progress through social interaction. Rules are situationally negotiated, with the formal rules of an organization lessening the impact of the informal organization on role. Within this paradigm, the possibility that rules prescribe action still exists.

Role prescription is therefore present in both Linton's functionalist and Turner's interactionist role theories, with role behaviour viewed as a consequence of actors following rules (Hilbert, 1981). The notion of rulegoverned behaviour (or role prescription) is important in discussions of role and role behaviour as internalized rules or expectations are central in explaining behaviour. Neither functionalist nor interactionist perspectives alone explain adequately the wide variety of human responses of different actors when confronting one another (Conway, 1978).

Hilbert (1981) argued that any model proposing role prescription must be challenged because roles do not require rules for correct procedure. Rather, people require rules when they decide they do. He argued that actors behave in social situations without the benefit of formal rules. When prescriptive guides are required, it is not to dictate action, but rather to know that they will be held accountable for the rules themselves. Furthermore, he argues that role cannot be seen as prescriptive, but rather as "an organizing concept used by members when they require it" (Hilbert, 1981; page 216). From this vantage, role 
is an organizing concept for shared conceptualizations (i.e., expectations and conceptions) used to maintain the stability of social interaction.

At a time of prevailing paradigm shifts in many disciplines, Lincoln (1985) argues that organizations are best viewed as complex and ambiguous, requiring involved actors to be mutually adaptive in order to achieve successful implementation. Equally important is the finding that programs must be tailored to fit local needs and that the best people to do this are not top level managers, but street level implementers, those in contact with clients or users (who can effectively implement and evaluate the program in question).

The ability to evaluate what works and what does not is invaluable to the organization in order to ensure a continuous process of re-evaluation and correction. Top-level managers lack the knowledge to make certain decisions; therefore it is imperative that they know where to obtain information, both inside and outside the organization (Weick, 1985). Identifying the stakeholders' conceptualizations (i.e., expectations and conceptions) to develop an effective role will permit those involved to develop patient care services which effectively meet patient care needs within the organization.

In conclusion, the traditional viewpoint held was that formal rules govern individual actors' behavior. The tendency was to establish a structure and then take a prescriptive approach to changing roles by reinforcing rules. More recent literature suggests that this model must be challenged because it fails to account for variations in individual behavior. Without buy-in and direct participation in the shifting of a structure to accommodate a new role, the prognosis for its success is 
weakened. Current literature suggests that shared conceptualizations (i.e., conceptions and expectations) among all concerned stakeholders provide the best footing for organizational change. This ensures a solution that fits optimally with the specific needs, constraints, and situation of an institution.

From this point forward, the term conceptualizations will be used in lieu of conceptions and expectations as it is an inclusive and acceptable term. Further, the stakeholders of the present study frequently used the terms conceptions and expectations as synonyms or flipped from one to the other in their discourse. While the literature discusses conceptions and expectations, the authors were unable to differentiate between the conceptions and expectations of the stakeholders.

\subsection{Development of Advanced Nursing Practice}

Hamric, et al (2005) studied the process of role development for Clinical Nurse Specialists (CNS) and developed a framework that may help understand the implementation of APN roles in the US. They described the process of role development of the Advanced Practice Nurse (APN) as a "multiple, dynamic, situational process where there is back and forth movement through the developmental stages each time there is a new undertaking" Hamric, et al (2005, page 85). Their description of role concepts and professional role issues includes descriptions of role stress (when role obligations are unclear or in conflict) and role strain (subjective feelings in response to role stress). In addition, role ambiguity can develop when expectations and responsibilities are unclear. Finally, there are also issues surrounding role conflicts among nurses or in relation to other groups such as physicians. 
Hamric, et al (1996) analyzed 100 questionnaires sent to Clinical Nurse Specialists. From this analysis, four phases of role development were described. For the purpose of this discussion, it is relevant to look at the first phase (Orientation). During this phase, there is enthusiasm and optimism on the part of the new CNS, who expects to meet her own and the institution's expectations by making changes. The tasks identified during this phase are to learn and clarify the role to self and others, explore expectations to see if they are compatible, and learn about the organization and its key players to establish a power base. Among the strategies to enhance APN role implementation at work during this phase, Hamric, et al (2005, page 128) cite the importance of "establishing mutually agreed upon role expectations", meeting with key players, and peer networking. Other work setting factors influence role definition and expectations, in turn impacting role conflict, ambiguity and incongruity. These factors include reasonable caseloads and access to a separate work area. Administrative factors found to enhance the effectiveness of the APN roles during this first phase include a good "fit between the goals and expectations of the individual and those of the organization" (Bryzinski: in Hamric et al, 2005; page 133). Clearly the organization plays an important role in determining the success or failure of new role implementation in advanced practice.

Woods (1999) used a case study method to identify factors influencing advanced nurse practitioners as they attempted to implement new advanced practice roles in clinical practice in the UK. She grouped these factors into three different categories: re-negotiating relationships, becoming an advanced practitioner, and deployment and environmental context. While she stressed that these results could not be generalized, they did provide evidence of their experience. Among the inhibiting factors cited by this author were control of scope of practice, and role 
development by managers and consultants. She also cited conflict with nurse managers, unclear role expectations and role definition as inhibiting factors. In addition, among the facilitating factors, the author cited support from nursing staff, medical staff and nurse administrators.

Lloyd Jones (2005) did a systematic review of the literature and synthesized their findings. She looked at a number of studies from both the US and the UK with the aim of reporting barriers or facilitators to role development of advanced practice roles in hospital settings. She concludes that the most important factors that hinder or facilitate the implementation of advanced practice roles are role ambiguity and relationships between advanced practice nurses and other staff groups. Furthermore, she concludes that these problems do not go away spontaneously. In order to minimize these problems, she recommends that clear role definitions be communicated to other stakeholders when new roles are introduced.

Rubin (1988) interviewed five advanced practice nurses in a hospital where a newly expanded nursing role was being developed with the aim of exploring the variability of expanded roles, as well as strategies to deal with problems encountered during implementation of these new expanded roles. This author states that there was variation in all of these expanded roles based on the expectations and beliefs of employers, nurses, and those who interacted with them in their various roles. She emphasized that each person involved with the development of this new role has expectations. She posits that promoting communication would help clarify role expectations, possibly reducing conflict and ambiguity as well as promoting satisfaction with the role. 
Patterson and Haddad (1992) reflect on the roles of advanced nursing practice (ANP) in Canada and conclude that boundaries of ANP are defined within the philosophical beliefs of their profession in order to meet the needs of patients, society, and nursing. They note that flexibility is an essential component of any advanced practice role if new avenues are to be explored and developed in healthcare. Van der Horst and Patterson (1993) emphasize the importance of clarifying the role functions and responsibilities of ANP roles for physicians, nurses and nursing administrators when these new roles are developed. These role functions and responsibilities include expert practitioner, educator, consultant/resource person, and researcher. It is essential to both Canadian authors that role development process for these new roles be flexible enough to permit ongoing negotiation and meet the needs of patients and stakeholders (Patterson and Haddad, 1992; Van der Horst and Patterson, 1993).

Haddad (1992) reviewed project objectives shortly after the implementation of Advanced Nurse Practice (ANP) roles in Ontario and describes factors that favor or impede the success of their project. Three outcome measures, which were indicators of a well-developed role, were acceptance, satisfaction, and a clear definition of the role for all stakeholders. Factors contributing to these outcome measures are detailed. Success of role definition and development include physician support of the role, and limiting the number of physicians who mentor ANP nurses. Factors that fostered acceptance and satisfaction included conceptualizing the role as a nursing role, providing non-clinical (or protected) time for preparation, and a strong desire from all stakeholders to collaborate toward a non-adversarial environment. In addition, adequate remuneration, reasonable number of hours and formal education increased satisfaction for ANP nurses. 
In their discussion of the six issues influencing the introduction of new advanced practice roles, Bryant-Lukosius, DiCenso, Browne and Pinelli (2004) recommend that the process be collaborative, based on clear goals for the advanced practice role. They caution stakeholders to support a nursing orientation, thus ensuring the role includes all functions (education, research as well as patient care). They emphasize the importance of stakeholder perceptions of the advanced practice nursing roles within the larger health system when planning these new roles. Failure to consider both the local and larger context leads to barriers later in the process. These barriers (at the health system level) include advanced practice nurses' competency being questioned due to variable educational preparation. Other examples include resistance from physicians to recognize and endorse these roles due to failure to address re-imbursement issues and physician income loss. At the local level, barriers include lack of resources for advanced practice nurses, and role conflicts. These illustrate the need for strong administrative support at the local level to promote role autonomy, role satisfaction, role clarity and innovation.

Role development is an ongoing process. Boundaries and scope of practice will continue to change and evolve as nurses' roles continue to adapt to societal needs and changes (Hickey, Ouimette, \& Venegoni, 2000). Role development is also social process, contingent on social context; not all parameters are fixed. The emergency nurse practitioner role is a break from both traditional medical and nursing practice. As this emergency nurse practitioner role is not yet in place in Quebec EDs, nor clearly defined in the current context, it is therefore impossible to develop the role from what emergency nurse practitioner does. Role behaviours are not defined; there are no role behaviours to mimic. 
Contrary to classic sociological views of role development, and in keeping with more modern views of role development and paradigm shifts, there is a strong need to consider local requirements and stakeholder views. The literature suggests that it is important to develop an effective role that maintains the stability of existing social interaction, using the conceptualizations of other involved actors. In addition, several authors studied the development of advanced practice roles post-implementation. While these provide us with important data, they overlook or omit completely how or whether such conceptualizations were used in the planning phases of role development. They also tell us very little about how the stakeholders' conceptualizations fit in with the position statement of the governing bodies.

\subsection{Research and Clinical Descriptions of the Emergency Nurse Practitioner Role and Its Evolution}

This third theme describes the evolution of the nurse practitioner role in the US and the UK; research findings from the literature describing the NP role as well as anecdotal descriptions, are presented.

\subsubsection{Role Evolution}

In the US and UK, the role of nurse practitioner in EDs have evolved more rapidly than in Canada. Both UK and US literature is rich in reported experiences following research findings and clinical reports of how the role has been developed.

Since its inception, the NP movement has generated much controversy, and much of the literature on nurse practitioners has focused on role 
definition and justification (Knafl, 1978). In the US, pressures stemming from lack of access to physicians by some segments of the population, and the movement toward a more active role for nurses in health care contributed to the emergence of the NP role. The beginning of the nurse practitioner movement is traced to a program at the University of Colorado Schools of Medicine and Nursing in the mid 1960s (Hamric et al, 1996). In the UK a number of factors converged to create a professional and legal climate conducive to the development of the emergency nurse practitioner role during the 1990s (Tye \& Ross, 1997). These factors included a reduced number of junior medical staff, an increased number of patients, policy reports encouraging the use of emergency nurse practitioners as a way of decreasing wait times and improving quality of care, and most importantly, changes in scope of practice provided the potential to revolutionize nursing work. These changes succeeded in accelerating the pace of role development of emergency nurse practitioner and other advanced practice roles by formally acknowledging the changing boundaries of clinical practice in EDs.

The nurse practitioner is one of five roles currently recognized under the umbrella of "advanced practice nursing" in the US (Hickey et al, 2000). It was the fourth to be developed, after nurse anaesthetist, nurse-midwife, and clinical nurse specialist. Until the 1980s, most US NPs were employed in primary care settings. In the 1990s, the need for nurse practitioners arose in acute and critical care areas to meet patient care needs within a collaborative model of practice. In addition, boundaries and scope of practice continue to change to meet evolving patient needs. It is thought that all professionals must evolve towards more collaborative and cooperative working modes in order to meet patient needs (Hickey et al, 2000). 
Controversies surrounding the role in the US included conflicts in both inter- and intra-professional relationships. Within the nursing profession, opponents of the NP concept argued that the development of the NP role would result in defection of nurses toward the medical profession, undermining the unique position of nurses in health care. Nursing educators and leaders were divided, creating barriers to mainstream education for NPs. The status quo of nursing establishment was disturbed by each of the advanced practice roles, but NP was most problematic because it challenged boundaries between medicine and nursing. Inter-professional conflicts, particularly with medicine have centered on control issues and the degree of independence NPs should be permitted. These conflicts have intensified as the NP role has evolved from a physician extender model to one with more autonomy. Economic competition was also at the centre of tensions between the two groups (Hamric et al, 1996).

Hamric et al (1996) noted that these historical struggles, neither "safe nor comfortable" have demonstrated the importance of unity among nursing leaders, and that both nursing and healthcare have benefited tremendously from these innovative and unique roles. The NP role is defined as:

An expert nurse clinician, who conducts comprehensive health assessments, makes a diagnosis, prescribes pharmacological and non-pharmacological interventions, and evaluates outcomes in the direct management of individual patients with acute and chronic illness and disease. In addition to conducting illness and disease management, the NP engages in health promotion and illness prevention management activities as an integral part of practice, 
practices in a variety of settings, providing direct care to individuals, families and communities by working independently or in interdisciplinary collaborative practice groups. (Hickey et al, 2000, pages 7-8).

\subsubsection{Research Descriptions of Emergency Nurse Practitioner Role}

Cole \& Ramirez (2000) report that NPs have been practicing in US emergency settings since 1975. All were trained in primary care based programs, and therefore were well versed in principles of health promotion, disease prevention and episodic care of non-urgent conditions. Recently, educational programs for Acute Care Nurse Practitioners have provided experiences for individuals interested in emergency services to enhance their ability to care for patients with emergent and urgent conditions (Cole \& Ramirez, 1997). As the need for skills, knowledge and experience unique to the ED was recognized, the School of nursing at the University of Texas Health Science Centre developed and implemented a unique program that focused solely on provision of emergency care. As the role in Emergency settings began primarily with the non-urgent population, the emergency nurse practitioner role focused mostly on primary care issues. As emergency nurse practitioners' became more experienced and innovative with the role, it evolved to include complex advanced practice and more advanced skills. Clearly, emergency nurse practitioners' work has evolved to include more complex procedures with emergent and urgent care populations in the US.

American literature reflects that the majority of emergency nurse practitioners are trained at the Master's level or higher. Cole \& Ramirez 
(2000) reported in his study that $46 \%$ percent were trained at the Master's level with an additional $20 \%$ at the post master's or doctoral level. This contrasts with UK literature, which reflects large discrepancies between training levels from one centre to another as well as lack of consensus on defining an NP. The recommendation for education for Advanced Practice nurses is that they be educated at the Master's level. However, as ambiguity persists in defining advanced practice, the precise form and of what education and training should be required for safe emergency nurse practitioner practice is unclear (Tye \& Ross, 1997). In addition, there is a move away from courses aimed specifically at emergency nurse practitioner practice, with a shift toward broader based NP curriculum that has resulted in less availability of emergency nurse practitioner practice settings available for graduates of emergency nurse practitioner program.

In the UK, Tye \& Ross (1997) report that the development of this role in the ED setting has been slower than in the US and began in the primary care setting. The first formal emergency nurse practitioner role was established in the UK in the mid 80's, and has evolved steadily since then. However, although these nurses are authorized to assess and treat patients in the accident and emergency department (A\&E), in the presence or absence of a physician, some nurses function as NPs without actually holding the title. Nevertheless, Tye \& Ross (1997) report that $63 \%$ of all emergency departments provided services using emergency nurse practitioners by 1995; this is a sharp increase as compared to the $9 \%$ reported in 1991 . This rising trend appears to be motivated by a number of factors that converged in the 1990s, forging a professional and economic climate conducive to this type of role development. These factors included a rise in the number of patients in the emergency departments, a number of reports encouraging the 
development of emergency nurse practitioner roles as one method of reducing wait times and improving quality of care, legal modifications to laws governing exclusive practice, and finally governmental policies that have significantly reduced the number of junior doctors hours (Tye \& Ross, 1997).

In the UK, emergency nurse practitioners are mainly involved in the management of minor traumas (Tye \& Ross, 1997). They also order radiological exams, prescribe certain medications, interpret certain X-rays. Jones (1996) demonstrated that emergency nurse practitioners in a pediatric ED setting could significantly reduce waiting time for inappropriate attenders or minor care pediatric patients. The emergency nurse practitioner role may be strictly of advanced nursing practice, or may include a rotational approach with a planned blend of emergency nurse practitioner role with traditional nursing duties. Finally, there may be an integrated approach wherein roles are combined and emergency nurse practitioner duties are carried out on an ad hoc basis (Tye, 2000). As clinical competence and confidence grows, there is room for expansion of present boundaries (Tye \& Ross, 1997).

In the US, emergency nurse practitioners focus on the care of non urgent and minor care patients. However, when acuity is high, the focus changes to collaboration with attending physicians to care for more acutely ill patients (Blunt, 1998; Sanning Shea \& Selfridge-Thomas, 1997). Emergency nurse practitioners' technical skills include the ability to evaluate and treat eye and ear injuries and infections, minor throat and dental problems, upper respiratory infections, lacerations, urinary tract infections, sexually transmitted diseases, vaginal complaints, minor skin conditions including burns, insect and animal bites, rashes, wounds and infections. They also evaluate and treat minor head, neck and 
extremity injuries and refill prescriptions (Blunt, 1998). They provide direct care to urgently ill patients, ensure follow-up for patients with sexually transmitted diseases, and follow-up on radiological discrepancies for patients seen in the ED who had X-rays with positive findings (reported after their visit).

Cole \& Ramirez (2000) studied the activities and procedures emergency nurse practitioners actually perform across the US, noting that the majority of articles related to NP practice in emergency care focus on fast track or minor care areas of the ED. However, this multi-center, multi-state study demonstrated that $45.8 \%$ of respondents work both the main ED and the fast track area and an additional $27.8 \%$ work only in the main ED. They emphasized that these figures demonstrate that the idea that emergency nurse practitioner's work only with non-urgent populations in fast track areas is inaccurate. Almost all respondents $(95,8 \%)$ indicated that they sometimes, or often, care for urgent patients; only $2 \%$ of respondents said they never took care of patients with emergent conditions.

Emergency nurse practitioners practicing in the ED setting may be as productive as their physician counterparts when treating patients. Several authors (Blunt, 1998; Buchanan \& Powers, 1997; Dowling \& Dudley, 1995; Sakr, Angus, Perrin, Nixon, Nicholl, \& Wardrope, 1999) studied data after the implementation of emergency nurse practitioners in their ED's with both their non-urgent patients and urgent care patients in collaboration with physicians. Their data analysis demonstrated emergency nurse practitioners' ability to be flexible in meeting the needs of the ED in reducing turnaround time, and treating higher acuity populations when necessary with greater or equal efficiency to their 
physician counterparts. In addition, they report a high patient satisfaction in patient satisfaction surveys.

Reveley (1998) studied the nurse practitioner triage role in the context of a group practice of eight general practitioners (GPs). The aim of this study was to evaluate the effectiveness of the NP triage role in the primary care context and explore the perceptions of both the primary care team and the patients. The study concluded that a properly trained NP can triage effectively and deliver appropriate care to patients with minor problems seeking same-day appointments.

Tye (2000) uses a case study evaluation of the NP role in an emergency department to evaluate the impact of the implementation of the emergency nurse practitioner role from the perspective of the healthcare professionals (stakeholders) most closely involved at the local level. Semi-structured interviews were used. Five major themes were identified in the data analysis: blurring role boundaries, managing uncertainty, individual variation, quality versus quantity and the organizational context. This author reports some consensus regarding the benefits of the role, such as improved waiting times and patient satisfaction, but also a large degree of ambivalence regarding the degree to which the role should be developed in the future, value for money and role configuration. He argues that the benefits and pitfalls must be considered within the context of local service provision. He concludes that this study illustrates the complexities of organizational, professional and legal issues associated with the role development on the boundary between two professional groups, as well as the importance of multidisciplinary support and continuing education to meet the challenges of this important role transition. 
Silvestri \& McDaniel-Yakscoe (2001) did a retrospective review of the follow-up of high- risk patients by NPs following discharge from an urban pediatric ER. Their centre identified the need for follow-up for certain population and recruited NP's to do this in addition to their clinical role. This review concludes that such change in practice increases patient satisfaction, improving communication between ED care providers and those in the community. In addition, this enhanced follow-up decreases the medical-legal risk related to reporting of lost or delayed results. It also permits the attending emergency physician to focus on other acute care and critical care issues.

Silvestri \& McDaniel-Yakscoe (2005) did a retrospective review of the NP's role development in the extended observation unit of an urban pediatric ED. They report that nurse practitioners are responsible for the care of selected patients in this unit. Their goal is to enhance the care of these patients, ensure continuity of care and simultaneously reduce admissions to their hospital. Their review shows that this unit is a success. Furthermore, the integration of an NP into this pivotal role is cost effective and permits for optimal use of human resources.

\subsubsection{Clinical Descriptions of the Emergency Nurse Practitioner Role}

In addition to these research findings, the literature is rich with descriptions of clinical initiatives of roles and responsibilities reported by nurse practitioners. The limitation of these reports is that they are not research, but clinical examples of how the role has evolved in different settings. 
Cole \& Catalino (1998) describe the emergency nurse practitioner's role in triage as peripheral. They advocate that although assessment of patients and assignment of triage category generally requires the expertise of an experienced emergency nurse, the triage nurse, to validate a triage category, may call upon the emergency nurse practitioner. Therefore it is vital that emergency nurse practitioner $s$ be experienced and skilled in triage. More importantly, during a disaster, the ED may be flooded with a high volume of patients whose conditions vary considerably in a short period of time. Because the disaster triage is significantly different from routine triage, with priority being the care of critically ill patients with the best chance of survival, the emergency nurse practitioner may be called upon to triage, as she/he possesses advanced assessment and treatment skills required. In addition, she/he would be called upon to coordinate care and assign patients to appropriate care areas. Finally, she/he may be needed to provide care to those who have been triaged.

Zimmermann \& Pierce (1998) report that emergency nurse practitioners initiate seeing all patients except for trauma patients. They take the initial history, order diagnostic work-up and treatment, and write admission orders. They refer to a physician when a patient's condition is beyond their scope of practice, but also perform such acts as suturing, endo-tracheal intubation, lumbar puncture, and needle thoracotomy. In addition, they are involved in inter-facility transport of patients in the place of physicians. These same authors report that in another setting NPs see acutely ill patients in the main ED using protocols. They also do the history and perform work-ups for patients with abdominal pain with gynecological examination. Benefits cited include the ability to keep things moving when physicians are occupied for long periods with critically ill patients, the ability to perform traditional nursing tasks when 
the need arises and using their special skills and knowledge to perform analysis data for quality assurance purposes.

Sica (2000) reports the use of emergency nurse practitioners to follow up positive laboratory, radiology, and EKG results of patients who were seen in the ED. In addition, the emergency nurse practitioner is responsible for documenting follow-up contact for all patients. She also contacts all patients who left without medical advice, or left before the ED visit was completed, and calls in prescriptions or prescription changes. The benefit of this role is cited as avoiding important complications and ensuing lawsuits.

Lininger (2004) describes one the functions of the pediatric nurse practitioner in the pediatric outpatient department with regards to sedation. This specialty role was created to address the specific needs of pediatric patients requiring moderate sedation for various procedures. The nurse practitioner, in collaboration with a physician, ensures safe administration of medication, appropriate monitoring and recovery of patients receiving moderate sedation. Their review of this change in practice reports high patient satisfaction, a higher standard of care for patients and less adverse effects related to sedation of pediatric patients.

Certain authors in both Canada and the US (Harahill \& Eastes, 1999; Robertson, 1999) highlight the importance of the NP's role in the trauma settings as one of coordinating care along the continuum, providing a recurring presence as the patient moves along through the system, thus ensuring communication between the patient, families, and all members of the health care team. The benefits cited include the ability to keep up their clinical skills, participating in quality improvement initiatives when 
they are not with patients, and promoting continuity. Kemp (1998) emphasized the importance of being able to use special skills of the emergency nurse practitioner while maintaining a family focus.

These research and clinical examples of how the emergency nurse practitioner role has developed and evolved in different settings demonstrates the importance of the clinical context in which the emergency nurse practitioner practices. They reflect the importance of unique and individual needs in each clinical setting. Because each ED has a unique culture and challenges, before a new role is implemented, it is important to consult those stakeholders who will be involved and therefore affected by this process. More importantly, conceptualizations with regards to this role must be known and considered if the role is to be successfully developed and evolve effectively for a particular setting.

In brief, the nurse practitioner role, one of five advanced practice roles, first evolved in the US. This role has been controversial since its inception, largely due to the fact that it challenged the boundaries between nursing and medical practice. Research and clinical (anecdotal) literature demonstrates that despite difficult beginnings, the emergency nurse practitioner role has evolved and continued to diversify, reflecting the various needs and expectations of an assortment of clinical settings. While this literature describes various role functions occupied by nurse practitioners, it does not tell us much about the nurse practitioner role and role functions in the pediatric ED. 


\subsection{Legal Aspects that Govem the Clinical Context for NPs}

In the US, where there is a longer emergency nurse practitioner tradition, the Emergency Nurses Association (ENA, 2001) developed Standards of Practice for nurse practitioners in the Emergency setting. These guidelines are complementary to the scope of practice guidelines (ENA, 1999) and are intended to direct the clinical practice of emergency nurse practitioners that have the educational and experiential background for practice in this specialty. In addition, these standards serve as a mechanism for evaluating nurse practitioner practice (ENA, 1999).

However, ENA emphasizes that the ultimate authority to practice in the NP role comes from individual state nurse practice acts. In addition, the credentialing body at a particular emergency setting may further restrict the role. While these standards of practice direct the standards of practice of emergency nurse practitioners they do not prescribe the management of patient conditions (ENA, 1999). Emergency nurse practitioners should adhere to the accepted practice guidelines for management of patient conditions.

Practice arrangements vary from state to state, according to regulations for advanced practice. Some states require that emergency nurse practitioners practice collaboratively with physicians, while others allow nurses to practice independently. While 50 states have prescriptive privileges for emergency nurse practitioners, they vary according to the type of medications that can be prescribed, and the degree to which physicians are involved in the prescriptive process. There is also 
variation in the necessity for national certification. While national certification may not be required by some states, it is important that certain standards be maintained. It is essential that all emergency nurse practitioners be experienced in the area of emergency nursing and be certified in Basic Cardiac Life Support, Advanced Cardiac Life Support, Trauma Nursing Core Course, and Emergency Nurse Pediatric Course (ENA, 1999).

While the authority to practice in the role of emergency nurse practitioner comes from the individual state nurse practice acts, clinical standards direct the practice of emergency nurse practitioners as well as reflect and recognize that the circumstances under which emergency nurse practitioners deliver care are vastly different than other health care settings for several reasons (ENA, 2001). Patients may be unknown to the emergency nurse practitioner, and may be unable to communicate due to their medical condition. In addition, the environment is often unpredictable and uncontrolled, and although patients may be triaged as having priority, care may be made difficult by extraordinary circumstances such as resuscitation, stabilization and crisis intervention (ENA, 2001).

In Canada, various laws at the provincial level provide for different advanced practice roles including that of emergency nurse practitioner. There are emergency nurse practitioners working in at least two Children's Hospitals in the province of Ontario, and a resolution has been passed in British Columbia's Vancouver General Hospital to integrate the role of emergency nurse practitioner within their emergency department in the next five years. There are, as yet, no nurse practitioners working in Québec emergency departments. 
L'Ordre des infirmières et infirmiers du Québec (OIIQ, 2001) proposed legislative changes to articles 36 and 37 of the laws governing nursing practice in the province of Quebec. This law had not been modified for thirty years, and the OIIQ called for changes that reflect the reality of current practice and the quality of current nursing practice (OIIQ, 2001). Until this change in legislation, advanced practice in Quebec has been practiced and developed by Clinical Nurse Specialists.

At the time this document was written, significant changes were underway in Quebec. Laws governing nursing practice and other health related professions underwent significant modification after the adoption of Bill 90 in June 2002. This Bill went into effect in January 2003, and includes the provisions related to nurse practitioners in specialty areas. The nurse skilled in her specialty area, and authorized by regulation could engage in one or more of five new activities:

- prescribing diagnostic examinations;

- using diagnostic techniques that are invasive or entail risks of injury;

- prescribing medications and other substances;

- prescribing medical treatment; and

- using techniques or applying medical treatments that are invasive or entail risks of injury.

In Quebec, the nurse practitioner in certain specialties can now carry out these activities (traditionally exclusive to physicians) if holding a specialized certificate conferred by the OIIQ. This requires successful completion of a licensing examination constructed jointly by the OIIQ and the Collège des Médecins (CMQ). 
For each specialty (i.e., nephrology, neonatology, cardiology), joint committees (OI/Q-CMQ) have been and will be set up with the mandate of making recommendations, based on the law and professional expertise, for regulations for nurse practitioners within a particular specialty. Joint committees have already made their recommendations for neonatal and nephrology specialties and discussions may be underway for cardiology.

In addition, the law calls for specific regulations governing medical practice and prescription of medication by specialty nurse practitioners to be jointly developed by the medical director of the specialty service and the Director of Nursing of the establishment in question. They will be responsible for jointly determining which activities respond to patient's needs and are therefore appropriate for specialty NPs to perform. Following the recommendations of both the Council of Nurses (CII) and the Council of Physicians (CMDP), these regulations governing the five new activities must be adopted by the establishment's governing board, in order to apply to NPs. The Quebec legal context resembles that of the USA, with the provincial legal context defining the scope of practice, and additional regulation in each institution further defining and governing the NP role and practice.

In conclusion, the laws governing nursing practice in the state or province and institution in which NPs practice largely determine the role functions of the NP. In Quebec, additional regulations from a number of governing bodies within individual institutions also determine NP practice. 


\subsubsection{Position Statements of Various Governing Bodies}

In the US, ENA (1999) recommended that educational preparation for the emergency nurse practitioners be at the Master's degree level. The knowledge and skills required for practice in the emergency setting are obtained through a university based program, continuing education and past experience. Because nurse practitioners will be exposed to patients of all age ranges across a variety of illnesses in an unpredictable environment where patient acuity and volumes fluctuate, they must possess a breadth and depth of knowledge concerning clinical management strategies. A university based graduate program should therefore include preparation in physical exam, advanced pathophysiology, advanced pharmacology, advanced diagnostic and therapeutic skills, and finally specialty content focusing on assessment and management of conditions encountered in emergency care.

In keeping with the philosophy of emergency care, the curriculum must provide sufficient clinical assessment skills to develop differential diagnoses, and a background in pathophysiology and pharmacology that permits them to select appropriate pharmacological agents for specific clinical conditions. In addition, they must also be well versed in nursing theory and research methods to develop innovative nursing practice (ENA, 1999). Given the multitude of clinical conditions NPs will be exposed to, they must have the background knowledge and laboratory experiences necessary to developing advanced diagnostic and therapeutic skills. At minimum, they must be able to close minor lacerations, interpret electrocardiograms, and perform microscopy of blood, urine and other body fluids. 
The Emergency Nurses Association (ENA, 2000) position statement on advanced practice in Emergency nursing included two roles: that of the Clinical Nurse Specialist (CNS) and the Nurse Practitioner (NP). In order to be recognized as an advanced practice nurse, the ENA stated that two criteria must be met. The first is that the nurse must have completed a Master's degree in a specialty area of nursing and the second is that he/she must be clinically active in that specialty area. They support and promote the use of advanced practice nurses in emergency care. In addition, they believe specialty organizations have the right and responsibility to define advanced nursing practice and to institute appropriate certifying procedures. Finally ENA (2000) states that the current health care crisis has adversely affected emergency health care systems, and created a need for innovative and cost efficient approaches to emergency care. They believe advanced practice emergency nurses are uniquely prepared to develop and apply theory, research and standards of care that enhance patient outcomes (ENA, 2000).

The Canadian Nurses Association (CNA, 2000) uses the term advanced nursing practice as an umbrella term that describes an advanced nursing practice that maximizes the use of in-depth nursing knowledge and skill in meeting the health needs of clients. They advocated that the boundaries of advanced nursing practice be extended so as to contribute to nursing knowledge and the advancement and development of the profession. They define advanced nursing practice (ANP) as advanced and expert practice grounded in knowledge that comes from nursing theory and other theoretical foundations, experience and research. They stated that there is a need for a framework to define advanced nursing practice (ANP) in Canada, which acknowledges the uniqueness of the Canadian health system. They emphasized the 
importance of reaching consensus on a national vision of ANP that retains enough flexibility to allow for jurisdictional variation and evolution of roles (CNA, 2000). They noted the importance of the American Association of Nurses position on advanced nursing practice, which describes three components that are common to all advanced practice roles: specialization, expansion and advancement.

Of particular note is that expansion includes knowledge and skills "legitimizing role autonomy within areas of practice that overlap traditional boundaries of medical practice" (ANA, 1995 in CNS, 2000). At the time this document was written, the most widely recognized role in advanced practice in Canada is that of the Clinical Nurse Specialist (CNS). New roles in nursing must develop in ways that promote excellence in client-centered care that are also in the public's best interest. Advanced nursing practice roles will develop in a variety of ways that reflect characteristics and competencies described by CNA. Advanced nursing practice roles could include, but not be restricted to, roles as they are known today, (for example, the clinical nurse specialist role and nurse practitioner roles). The nurse practitioner is defined as a registered nurse with advanced knowledge and decision-making skills in assessment, diagnosis and health care management. Practice is based on in-depth knowledge of nursing gained through advanced education and practice (CNA, 2000).

The forum national sur la planification de main-d'oeuvre infirmière (2001; in OIIQ, 2001) emphasized the need to pursue new roles in advanced nursing practice as both a solution to meet the demand for these services in emergency departments, CLSC's, nephrology, psychiatry and long term care facilities, and as one solution to the 
nursing shortage by valuing the precious expertise nurses bring to the profession.

L'Association des infirmières et infirmiers des urgences du Québec (AIIUQ, 2000) made recommendations to the Ministry (of Health) with regards to the education and training of ED nurses. To enhance advanced nursing practice, their recommendations included the services of a CNS as well as those of a nurse practitioner for all emergency departments.

The Clair Commission's mandate was to evaluate the different aspects of healthcare organization and services. It envisioned the development of two advanced practice roles as one solution to address serious difficulties with regards to accessibility to services, coordination and continuity of care (OIIQ, 2001). The integration of nurse practitioners into primary care settings with the collaboration of physicians was proposed. More importantly, it was recommended that nurse practitioners be integrated into the network via "projets d'intégration", specifying that they possess a Masters degree and be prepared with clinical expertise in their specialty and receive some medical training within their specialty $(O / / Q, 2001)$. The identified priority for these new positions is development of the nurse practitioner role in emergency departments and the introduction of an advanced triage role as part of their mandate (OIIQ, 2001). This proposal echoed that of the Ordre des infirmières et infirmiers du Québec (OI/Q), described above.

These various position statements summarize the different positions which nursing organizations have taken in favour of the development of the nurse practitioner role in various specialties, with higher education, 
and under specific conditions. The position statements are in favor of having the education requirements at the Masters level.

\subsection{Conclusion}

In closing, this literature review has mapped the role theory and evolution of a professional role, research and clinical descriptions of the emergency nurse practitioner role and its evolution, legal aspects governing the clinical context for NPs, and position statements from various organizations which serve as guidelines for emergency nurse practitioner practice. Together, these themes illuminate issues that collectively characterize the boundaries of role definition of the emergency nurse practitioner. Current role theory literature indicates the importance of obtaining and using stakeholders' conceptualizations in order to develop roles in response to local needs. Literature on this controversial role in post-implementation is well documented, descriptions of the planning phase are sorely lacking. There is little Canadian literature on the nurse practitioner role in general, and none of this literature describes role functions in Canadian pediatric emergency departments. 
CHAPTER 3

METHODOLOGY 


\section{METHODOLOGY}

A descriptive qualitative design was selected to gain a better understanding of the conceptualizations of the NP role in the pediatric $E D$, as well as the social factors favouring and impeding these in the early planning stage. The design of this study was influenced by various qualitative methods, particularly grounded theory, which permits identification and categorization of elements, and exploration of their connections, in addition to exploration of causal conditions, context, strategies and consequences which explain the emergence of the phenomenon (Chenitz, 1986; Coffey \& Atkinson, 1996; Miles \& Huberman, 1994; Strauss \& Corbin, 1990). As little is known about the conceptualizations of this role in the pediatric emergency setting, it was appropriate to use a descriptive qualitative method to explore the stakeholders' conceptualizations of the emergency nurse practitioner role.

\subsection{Site and Participant Selection}

The research took place in a pediatric university hospital in Montreal. Interviews were held in each of the participants' offices. Consistent with a descriptive qualitative design, purposeful sampling was employed (Patton, 1990). The researcher selected information-rich cases in order to better understand the issues of central importance, thereby illuminating the question under study. Eleven participants were recruited by the study. The amount of data to be collected was determined by the thoroughness and quality of data, under the supervision of the study supervisors. 
While the role under study is a nursing role, its development involves stakeholders from other disciplines, whose conceptualizations are essential for successful role development. Because physicians, nurses and hospital administrators are implicated in this role, stakeholders from each of these three groups were selected. Experienced ED physicians, nurses and administrators of the hospital in question were selected, on the basis of their ED knowledge and experience, as well as knowledge of the emergency nurse practitioner role. Nurses and physicians were selected on the basis of meeting as many of the following criteria as possible:

- understand the organizational functioning of the ED;

- have worked extensively or currently work in the ED; and

- have some familiarity with the nurse practitioner role from previous reading or exposure to the emergency nurse practitioner role.

The senior staff nurse(s) were selected in consultation with the acting Head Nurse, and the ED physician(s) in consultation with the Medical Director, on the basis of having at least three years of experience working in the ED, in addition to the previously stated criteria.

Participants were contacted by telephone, with written follow-up communication. Participation was requested following a short description of the study, the method, the goals of the study, and what was required of them. They were notified in writing of the study's purpose and methodology. The confidential nature of the research data was emphasized. Each was asked to agree to a 60-minute (maximum) audio taped interview in their respective offices to minimize inconvenience. Written consent was sought. Please see Appendix B. 
Demographic data were collected at the end of each interview, including gender, occupation, number of years in a profession and current position. Please see Table I. All were asked if they had worked in an institution that employs emergency nurse practitioners. Out of eleven participants recruited for the study, four were ER physicians, four were ER nurses and three were hospital administrators. The hospital administrators included a senior hospital administrator, a senior member of the nursing leadership group, and a senior executive member of the Council of Physicians, Dentists and Pharmacists.

Three of the participants were men and eight were women. Only two of the participants were familiar with position statements on the NP role from various organizations. None of the participants had worked with an emergency nurse practitioner, but five of the participants had worked with a Nurse Practitioner in another setting, or had been instrumental in setting up an NP program in their setting. Participants had professional experience ranging from five to 31 years and had occupied current positions from six months to 15 years. 
Table I - Participant Demographic Data

\begin{tabular}{|c|c|c|c|c|}
\hline Gender & Occupation & $\begin{array}{c}\text { \# years } \\
\text { in present } \\
\text { employment }\end{array}$ & $\begin{array}{c}\text { \# years } \\
\text { in current } \\
\text { position }\end{array}$ & $\begin{array}{c}\text { Prior work } \\
\text { experience } \\
\text { with } \\
\text { emergency } \\
\text { nurse } \\
\text { practitioner }\end{array}$ \\
\hline$F$ & Nurse & 22 mos. & 17 yrs. & No. \\
\hline $\mathrm{F}$ & Nurse & 22 mos. & 16 yrs. & No. \\
\hline$F$ & Nurse & 5 yrs. & 5 yrs. & No. \\
\hline$F$ & Nurse & 2 yrs. & 24 yrs. & No. \\
\hline $\bar{M}$ & Physician & $15 \mathrm{yrs}$. & 31 yrs. & $\begin{array}{l}\text { No, but briefly } \\
\text { in another } \\
\text { setting with NP. }\end{array}$ \\
\hline$M$ & Physician & 7 yrs. & 10 yrs. & $\begin{array}{l}\text { No, but briefly } \\
\text { in another } \\
\text { setting with NP. }\end{array}$ \\
\hline$M$ & Physician & $2.5 \mathrm{yrs}$. & $7 \mathrm{yrs}$. & No. \\
\hline $\mathrm{F}$ & Physician & 20 yrs. & $21 \mathrm{yrs}$. & $\begin{array}{l}\text { No, but briefly } \\
\text { in another } \\
\text { setting with NP }\end{array}$ \\
\hline$F$ & Administrator & 13 yrs. & $15 \mathrm{yrs}$. & No. \\
\hline $\bar{F}$ & Administrator & 6 yrs. & 22 yrs. & $\begin{array}{l}\text { No, but briefly } \\
\text { in another } \\
\text { setting with NP }\end{array}$ \\
\hline$F$ & Administrator & $6 \mathrm{mos}$. & $30 \mathrm{yrs}$. & No. \\
\hline
\end{tabular}




\subsection{Data Collection Process}

Stakeholders were interviewed between May 2004 to November 2004, using semi-structured interviews with pre-determined questions and additional questions emerging from data and the analysis process (Coffey \& Atkinson, 1996; Miles \& Huberman, 1994). All interviews were audio taped with the participant's permission. Data were transcribed and subsequently the content was analyzed. An interview guide is included in Appendix A.

Probes (questions) were used to encourage the participant to continue or to elaborate. Such prompts encouraged the participant to clarify or give further detail (Chenitz, 1986).

The researcher concurrently collected, coded, and analyzed the data. This process of data collection ensured the theoretical sampling process by verifying that data collection was controlled by the emerging theory, rather than a preconceived theory (Glaser \& Strauss, 1967). An experienced qualitative researcher who is also co-supervisor of the study provided ongoing supervision.

\subsection{Development of the Interview Guide}

The interview guide was developed to elucidate the participants' conceptualizations of the NP role in the pediatric ED. (See Appendix A) Questions were divided into four distinct sections: 
- The aim of the first section was to obtain and record conceptualizations of the NP role (i.e., what participants see the NP doing, and with which populations).

- Questions in section two were designed to obtain participants' conceptualizations of the role development process. For instance, how should the role be developed, who should be involved in the process, and who should be consulted?

- In section three, the questions were intended to gain information on participants' conceptualizations of the ER context and particular aspects which might enhance or impede the development of the emergency nurse practitioner role in this particular environment.

- Finally, in section four, the questions were formulated to acquire a better understanding of the participants' knowledge of the legal context and position statements of governing bodies.

The questionnaire was developed to clarify and record participants' conceptualizations of these four large themes; the same themes explored in literature prior to data collection, and extensively illustrated in Chapter Two. Two experts validated the content of the interview guide.

\subsection{Data Analysis}

One of the processes used during qualitative analysis is coding, which in practice is a method of reducing data collected into analyzable units. The coding process permits the researcher to achieve the goal of generating concepts from data (Coffey \& Atkinson, 1996). Codes, data categories and concepts are all closely related, converting raw data into theoretical concepts. This study used the coding method proposed by Strauss and Corbin (1990), without committing to theory development, 
as the phenomenon under study was not a process. The methods proposed by Strauss \& Corbin (1990) and Paillé (1994) for analysis in grounded theory include various stages of coding, of which the following two were retained: open coding and axial coding.

The first stage of analysis (open coding) pertains to naming and categorizing phenomena through close examination of data. During this phase, interview transcripts were broken down into discreet parts, examined closely, and compared for similarities and differences, allowing for fine discrimination and differentiation among categories. Discovery of concepts was the focus of this phase of analysis. The student researcher compared the participants' conceptualizations, looking for similarities. (See Appendix C; Tables I, II, and III). Once concepts were identified, the researcher was able to group similar conceptualizations under a common classification. Labels or concepts were then grouped into categories under more abstract terms.

Characteristics of each category were identified and compared. By exploring the range and variation of each category, the researcher increased her knowledge of each concept (Strauss \& Corbin, 1998). During open coding, many different categories were identified. Some of these pertained to a phenomenon, and others referring to conditions, actions/interactions, or consequences were relabelled as subcategories (Strauss \& Corbin, 1998). This enabled identification of patterns with corresponding variations, ultimately leading to subcategories as conceptualizations were grouped (categorized). This process permitted better discrimination of themes (categories) and the development of subcategories. The identification of these subcategories permitted the researcher to learn about how, why, where, when phenomena occurred. 
The second stage of analysis, axial coding, refers to a set of procedures to examine potential connections between categories. The process of linking categories and corresponding subcategories enabled the researcher to form more precise and complete accounts of phenomena. Each category or phenomenon was an event, issue, problem or happening that was defined as significant for the participants.

The subcategories, when differentiated from the categories, provided greater detail on where, when, how, who, and with what consequences, thus forming more complete and precise explanations of each concept, providing greater "predictive ability" (explanatory power). The study ensured that the four essential tasks (Strauss \& Corbin, 1998) during this phase were carried out:

- laying out the properties of a category and their dimensions;

- identifying conditions, actions/interactions, and consequences associated with a phenomenon;

- relating a category to its subcategories; and

- looking for cues on how they relate to each other (relationships between categories and subcategories).

This process enabled the researcher to determine structure, (providing explanations for why phenomena occur, and corresponding complexities). The researcher coded for relationships to gain an understanding of phenomena permitting improved comprehension of conditions, actions/interactions, and consequences. The focus was to determine the conditions under which persons responded to an event with action/interaction, and with what resulting consequences (Strauss \& Corbin, 1998). 
Relational statements were made to explain links between concepts. The dimensions, categories and subcategories and how these relate to each other are illustrated in Figures 1, 2 and 3 in the following chapter.

These statements made at the conceptual level were validated and further elaborated through continued comparisons of data. The researcher proceeded naturally through these two phases, and not sequentially to ensure density and explanatory power of the findings.

\subsection{Methodological Rigor}

In order to ensure methodological rigor, the researcher used the criteria described by Sandelowski (1986). These are truth value, applicability, consistency, and neutrality.

In qualitative research, the criterion against which truth value (internal validity in quantitative research) can be evaluated is credibility. Credibility is assured when external researchers or readers recognize the experience when confronted with it (after having read about it in a study). Prior to presenting preliminary data in Medical Emergency teaching rounds to both ED nurses and physicians, the student researcher asked them to briefly summarize their expectations of the emergency nurse practitioner role. Their responses were similar to those of study participants, supporting the credibility of this data.

Applicability (external validity in quantitative research) refers to the transferability of findings. In qualitative research, the criterion against which external validity should be measured is "fittingness". Fittingness is achieved when findings can 'fit' into contexts outside the study situation when people outside the context view the findings as meaningful and 
applicable in terms of their own experiences. Findings must be well grounded in the life experiences studied and reflect typical and atypical situations.

To ensure credibility and fittingness, several strategies were employed. These strategies included validation from ED stakeholders, as well as verification of the representativeness of the data including both typical and atypical situations. The researcher ensured that the findings (categories) related to more than one group of stakeholders. See Tables II, III, and IV in Appendix C.

Consistency (reliability in quantitative research) can be ensured in qualitative research by auditability. A study and its findings are auditable when another researcher can clearly follow the "decision trail" used by the investigator.

The researcher ensured auditability by keeping organized memos and field notes. In addition, the data collection and analysis processes were monitored by the study supervisors and are extensively described above.

In addition, the researcher produced the memos, and documents demonstrating coding instructions and placement of data into categories, and the way different elements of the data were linked.

Confirmability (neutrality in quantitative research) is the final criterion of methodological rigor. Confirmability is achieved when auditability, truth value, and applicability are established (Sandelowski, 1986). 


\subsection{Ethical Considerations}

The ethical and scientific committees of the Université de Montréal and the hospital in question approved the study. Participants were informed about the study, its specific aim, and data collection procedure by means of a written document provided upon request for consent. Participation was entirely voluntary. There were no anticipated consequences associated with either participation or abstention. Concealing the participants' identities ensured confidentiality. All written and recorded information were, and will continue to be kept in a secure place for five years (from the time of data collection).

\subsection{Conclusion}

A qualitative method influenced by grounded theory was selected to elucidate information on the phenomenon (conceptualizations of the emergency nurse practitioner role in the pediatric ER). Purposeful sampling was used to select participants knowledgeable about the pediatric emergency context and the emergency nurse practitioner role. After obtaining authorization from both the university and the site in question, data were collected and analyzed using the method proposed by Strauss \& Corbin (1990). This process permitted the researcher to analyze and organize the data in a meaningful way. Data were categorized. Subsequently, sub-categories explaining the categories in more detail were developed. The categories and sub-categories were then organized around a central dimension. This data is presented in the next chapter. Methodological rigor was respected to ensure the quality of the findings. 
CHAPTER 4

\section{RESULTS}




\section{RESULTS}

This chapter presents the research findings and is divided into three sections with sub-sections. Each section examines the principal themes that correspond to the research questions:

- conceptualizations participants held of the emergency nurse practitioner role;

- conceptualizations participants held of the role development process; and

- contextual considerations favouring or impeding the development of the pediatric emergency nurse practitioner role.

A schematic representation (figure) of the dimension, its categories and subcategories is presented at the beginning of each section.

\subsection{Conceptualizations of the Emergency Nurse Practitioner Role: Questioning of the Medical and Nursing Dimensions of the Emergency Nurse Practitioner Role}

This section presents the stakeholders' conceptualizations of the emergency nurse practitioner role in the pediatric ER. Both the nurse and physician stakeholder groups had a lot to say about what the emergency nurse practitioner role should include. The administrators on the other hand, seemed content to leave the other two stakeholder groups to determine the role functions. As demonstrated in Figure 1 below, the dimension "questioning the medical and nursing dimensions 
of the emergency nurse practitioner role" is detailed, along with its three themes and corresponding sub-themes;

- Extend nursing' role beginning at triage;

- Bridge gaps between nursing and physician roles;

- Limit emergency nurse practitioner to selected populations

Participants view the role as one that crosses the traditional boundaries between traditional nursing and medical roles. There was clear expression that this is a nursing role that, in part, includes acts traditionally reserved for physicians. Almost all participants illustrated this dimension. For example:

"...the conception of these kinds of roles in the variety of areas really needs to be viewed as something new. A hybrid, not a replacement for... (A1:276-278)."1

"The way I perceive the NP is to me, she is part clinician, Nurse Clinician, and her role is extended to having to practice part of a medical act... (N4: 1-3)."

"I would see them performing a role somewhere between the physicians and nurses (P1: 6-7)"

1 Selected quotes are presented to illustrate each theme. To simplify notation for the quotations, $\mathrm{P}=$ physician, $\mathrm{N}=$ nurse, and $\mathrm{A}=$ administrator. The number assigned to each participant does not necessarily correspond to his or her rank in Table I. 
Sub-category

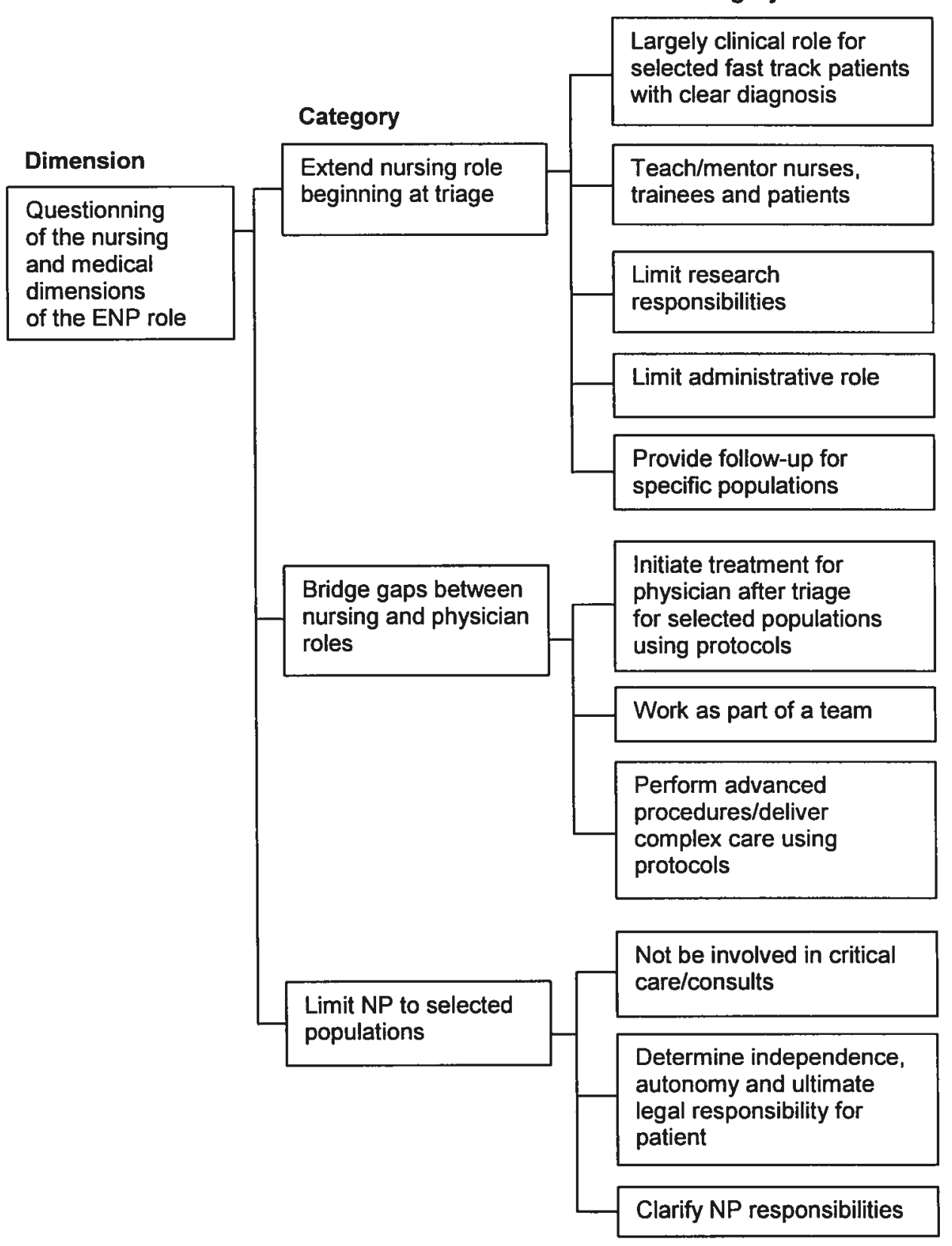

Figure 1 - Stakeholder Conceptualizations of NP Role 


\subsubsection{Extend Nursing Role at Triage}

Participants expressed that they see this role as an extended nursing role beginning right at triage (the beginning of an ER visit for a patient). Their statements define this role as a nursing role, which would permit nurses to legally put their knowledge and skills to work, enhancing patient care on initial contact, at triage. Once a child has been identified as prioritized, there are some initiatives an NP could take to improve accessibility and reduce waiting time.

"NPs could carry out this (triage) role in a more in-depth fashion and could provide at least some backbone to a service need this is definitely there. (A2: 7-9)."

"... at triage, I could see her, there's been talk right now, and more and more, as extending the role and responsibilities at triage. (N4: 192-195)."

"To me, the NP is more touching the 'physician type work' than the nurse. I don't think the NP will remove any work from the nurse. I think it is just an extension... (N2: 71-74)."

\subsubsection{Clinical role for selected fast track patients with clear diagnosis}

While participants support this nursing role and are in favour of extending it, they view it primarily as a clinical role, whereby the NP intervenes with selected populations only. One of the populations described by many participants was non-acute (Categories 4 and 5 of the Canadian triage and assessment guidelines) who present in large numbers, but could most often be seen in non- emergency settings. 
"... what we call fast track, so patients with categories four, five maybe. Little things, patients with less acute diagnosis (N2: 25-27)."

"I guess I would see it that they would be given a category of patients, say categories four and five... (P1: 63-66)."

"I think the areas where there is more likely to be a specific diagnosis or non-toxic children would be easier for them (P1: 103-105)."

\subsubsection{Teach, mentor nurses, trainees and patients}

Although participants prioritized the clinical (patient care) functions of the role, they had expectations that the emergency nurse practitioner be involved in teaching patients, as well as mentor/teach nurses, and medical and nursing trainees.

"NP would be sort of a leader in teaching of the nursing staff that is there, and the fact that she is in the same profession as they are, in a different level maybe, but I think the 'openness' of the nursing staff would be bigger... (N3: 189-192)."

"I think certainly education can be a big role. My belief is however, the more we get people specialized, the less clinical care they tend to do (P1: 272-275)."

"I think this person could have a very active role in continuing education...bringing some experience and bringing questions... (P4: 231-239)." 


\subsubsection{Limit administrative role}

Certain participants, particularly physicians, expressed that the nurse practitioner should have some administrative role functions, which differs from the current leadership structure where the "charge nurse" has a central role in ensuring administrative functioning on a daily and continuous basis. This aspect may reflect a need to maintain the role's clinical focus, while utilizing potential leadership qualities to foster better patient flow and care prioritization.

"So maybe somebody in that (NP) group has to be a leader of leaders, somebody who has, I would think, with some administrative background as opposed to just skills with patients and colleagues (P2: 74-77)."

"...I see them involved in some of the administrative aspects of the Emergency department as to patient flow and deciding on triage and patient disposition and discharge planning, things like that (P1: 29-34)."

\subsubsection{Limit research responsibilities}

Nurses and physicians saw research responsibilities similarly: limiting the time an NP would spend on research to avoid interference with clinical aspects of the role.

"...l am not sure the role of the nurse practitioner is research.

They can facilitate research. They can be involved in the recruitment of research, they can come up with excellent ideas, but I do not think they should be hired to plan projects 
and write grants. I thought they would be developed to give patient care... (P1:301-310)."

"...if we think of the advanced role she has, the other thing besides her daily role...there is potential for this nurse to participate in more research... (N3: 156-160)."

\subsubsection{Provide follow-up for specific populations}

Participants (both nurses and physicians) saw an extension of the nursing role for the NP to provide follow-up for selected at-risk populations.

"...the follow-up or re-assessment of patients or by phone, or of some patients that were seen in the ED. Or maybe a follow-up to the Emergency, I don't know (P4: 217-220)."

"...the follow-up, the more I think about it, it is not a bad thing...I am not saying I see her doing that completely, but I see a certain population that needs that kind of thing (N4: 355-359)."

"I am thinking of those kids that are followed in different clinics that come (to the ER) because their clinics are closed. Would she be able to do a link of some sort between what is happening in the ER and their clinic? (N4: 360-365)."

This theme illustrates participants' conceptualizations of the pediatric emergency nurse practitioner role as a largely clinical extension of the nursing role, beginning at triage with selected non-acute populations 
presenting with a clear diagnosis. If clinical aspects dominate the role, it is expected that administrative and research responsibilities would be limited. There are strong expectations that the emergency nurse practitioner would also be mentor and teacher to peers, patients, and parents, providing follow-up to selected populations.

\subsubsection{Bridge Gaps Between Nursing and Physician Roles}

The second theme of this dimension is "bridge gaps between nursing and physician role", with seven sub-themes. Participants explore the notion of modifying nursing responsibilities to close or bridge gaps between what nurses and physicians currently do in the pediatric ER setting.

"Well, NP means obviously that a nurse has been trained or delegated to do advanced things. I was going to say medical acts, but I think that is a poor term. And I think nursing acts is also a poor term. And I think they close the gap as much as they fill the gap between physicians and nurses in certain clinical situations (P2: 337-344)."

"...they (physicians) are trained for emergency and trauma. I think this is where the NP would benefit most, providing follow-ups and teaching. "Nursing has a whole different concept of "medicine", we see things from a different perspective and this is what the population needs, evaluating needs and resources (N3: 66-73)."

"...NPs are viewed as a solution right now. What I understand of Law 90 is that there is more "chevauchement" (overlap) between the different professions (N3: 66-73)." 


\subsubsection{Initiate treatment for physician after triage for selected populations using protocols}

Where nurse participants expressed conceptualizations of the nurses' role being "extended", other participants, particularly physicians, expressed conceptualizations of the NP initiating treatment, using protocols, for specific and pre-determined populations prior to a physician seeing a patient.

"It could be helpful to have an NP at triage to accelerate the process and decide who needs $x$-rays, decide if we need to do some blood work (P4: 8-10)."

"What I see is the initial assessment and the other sorts of things before the physician would normally be available to see the patient as taking place (P2: 350-353)."

"And then you know looking at the fracture and knowing it fits the criteria for reduction, make sure the IV is placed, and that keeping the protocol is automatically engaged. I should not have to confirm what we have already agreed upon... (P2: 391-396)."

\subsubsection{Perform advanced procedures/deliver complex care using protocols}

Both nurse and physician participants described their conceptualizations identifying specific clinical activities they see the NP participating in. They see her, in part, delivering complex care and performing advanced procedures such as bagging, placement of oral airway, and recognizing 
and intervening appropriately if airway problems occur during procedures requiring sedation. This type of activity is specifically with acutely ill patients, barring those in critical condition.

"...there should be one person (MD) doing the procedure, and one person (NP) looking after the patient. The NP would presumably have the airway skills etc if somebody needed to be bagged or have an oral airway inserted, that sort of thing. If they (patient) had some sort of reaction to the Ketamine... I would expect the NP to identify it early (P2: 27-34)."

"The physician would do the intubation and I would see her (NP) giving the actual medication for the rapid sequence intubation. She could also be present for the sedation protocol we have, the Ketamine protocol. She could be the person doing the part of managing the airway when we do a procedure (N4: 64-70)."

\subsubsection{Work as part of a team}

In an ER context, where many different professionals and other types of workers work closely together, the notion of teamwork is key. Participants expressed conceptualizations that this notion be extended to the NP and her place in the ER. They see her maintaining a patient care focus; collaborating with other professionals, and interacting with the rest of the team rather than working in isolation.

"So, I think it would be somebody who would participate as part of a global health care team in the ER. I would not see them 
working independently, I would see them working with physicians, nurses, child life workers, various people (P1: 1-6)."

"I would expect that (experience and leadership) would smooth the teamwork between the physicians, the nurses and other caregivers in the Trauma room, in the rest of the surgical ER (P2: 64-70)."

"... I think particularly in am emergency pediatric setting, you still have to keep the concept of teamwork and having a multidisciplinary approach to it (N3: 22-25)."

This second theme illustrates participants' conceptualizations of the pediatric emergency nurse practitioner working as part of a multidisciplinary team, bridging gaps between the roles nurses and physicians currently hold in pediatric EDs. Specifically, initiating treatment to pre-determined populations using protocols prior to a patient seeing a physician, and using predetermined guidelines to perform complex care and procedures.

\subsubsection{Limit NP to Specific Populations}

This third and final theme of this dimension with its three sub-themes finalizes this section on conceptualizations describing the emergency nurse practitioner role. In this theme, participants elaborated upon the importance of limiting an emergency nurse practitioner's practice to selected populations for diverse reasons, particularly diversity of clientele. It was generally felt that it would be impossible for him/her to meet all needs. Therefore the focus should be on the needs and what the law permits. In addition to limiting care to specific populations, 
participants also stressed the importance of determining what degree of autonomy and independence the NP would have within the ER context.

"Well, the problem with the ER is that you have all the specialties and you cannot re-specialize in all those specialties. It's impossible (N1: 186-188)."

"I think it would be to initiate some treatment in a well identified disease or complaint that may improve care given to the patient, or length of stay, or time to final disposition (P3: 1-3)."

"I would see them (NP) as somebody who could help select out those patients who right from the onset, look as though they have a problem that would be within their defined roles and objectives for health care (P1: 8-12)."

\subsubsection{Not be involved in critical care/consults}

While participants were in favor of NPs having an important role with acutely ill patients, performing advanced procedures, and initiating treatment for physicians, they were not in favor of the NP being responsible for critically ill patients. Nurses and physicians conceptualizations of the NP role with this unstable and minority population in the pediatric ER, were limited to "bringing control to chaos" (uncontrolled situations), rather than performing highly specialized and technical skills such as intubations. It was generally felt that if a consultant is required, then physicians should take these cases and perform the specialized care required. 
"I think that I don't see them getting involved in extremely complex cases... (P1: 21-23)."

"I don't think that we need to add people to be able to intubate and putting some chest tubes and central lines... (N3: 47-49)."

"More complex ones where we consider getting plastic surgery involved, 1 think would be beyond their scope ... (P2: 12-14)."

\subsubsection{Determine independence, autonomy and ultimate responsibility for patient}

With many of the participants in favor of an NP limiting work to specific populations, the question of the degree of autonomy with those selected populations arises. Participants, including nurses, physicians and administrators saw the need for this question to be addressed, not only in relation to what the law stipulates, but also in terms of their conceptualizations. Many participants did not have a clear sense of the law, but perceived that the question of responsibility needs to be discussed and defined. It is unclear who has ultimate responsibility. They saw the NP working alongside the physician, consulting as necessary, maximizing efficiency, yet respecting the law.

"It would probably end up being what is best for the functioning of the ER (A1: 218-220)."

"I think they have to be able to function fairly independently or have back-up available (P1: 20-21)." 
"OK, does she work under a staff (physician) every shift? (N1: 312-313)."

\subsubsection{Clarify NP responsibilities}

With so many unresolved questions on how the NP role will work, many physicians and nurses raised the importance of determining the NP's level of autonomy and responsibility. The conceptualizations were that the level of responsibility must be clear to both parents and other stakeholders in order to avoid confusion and chaos.

"I do this, but I do not do that, and it can make it very confusing for staff, parents to know who is looking after them and who is not, and the qualifications, and would they get mixed up with the (medical) students? (P1: 195-200)."

"Well, the NP has to be well identified.... She has to be introduced as the NP.... There must be protocols saying she can do this, she can do that (N1: 276-281)."

"Nursing wise, this is going to be challenging because it's a role that has to be well defined, it's a bit of nursing and a bit of medicine (A2: 44-46)."

The third and final theme of this dimension illustrates the participants' conceptualizations of the pediatric emergency nurse practitioner as an autonomous practitioner, limited to selected populations, with a clearly determined level of autonomy, independence and responsibilities. They do not see her as having this role with critically ill patients, or patients requiring outside consultants. 


\subsubsection{Conclusion}

In conclusion, 11 stakeholders (including nurses, physicians and administrators) described their conceptualizations of the NP role in the pediatric ED. These include a largely clinical role with some teaching/mentoring and more limited research and administrative roles. They view the role as one where the NP intervenes, beginning at triage with selected populations. These populations are both fast-track (nonurgent) patients as well as other selected acutely ill patients. They do not see her as involved with critically ill patients or those requiring consults. Rather, they conceptualize the NP using protocols for these pre-selected populations to extend the current role of the nurse, thus bridging the gap between nurses' and physicians' traditional roles.

There is much convergence between the stakeholders' conceptualizations. One area of divergence is that the nurses describe the role as an extension while physicians more specifically expressed initiating treatment for specific populations prior to seeing a physician. There is some divergence here between the vision of the nurses and the physicians. While the nurses' conceptualization of this role supports a strong nursing orientation, the physicians' conceptualizations were more oriented towards physician replacement or support. The following section describes the conceptualizations of the participants in relation to the role development process. Finally, both nurses and physicians expressed that the role bearing responsibility for the patient must be clear to all stakeholders.

With many of the participants in favor of an NP limiting work to specific populations, the question of the degree of autonomy with those selected populations arises. Participants, including nurses, physicians and 
administrators saw the need for this question to be addressed, not only in relation to what the law stipulates, but also in terms of their conceptualizations. Many participants did not have a clear sense of the law, but perceived that the question of responsibility needs to be discussed and defined. It is unclear who has ultimate responsibility. They saw the NP working alongside the physician, consulting as necessary, maximizing efficiency, yet respecting the law. They agreed that teaching and mentoring is important, and that research responsibilities must be minimized to ensure that the role retains its clinical focus.

\subsection{Conceptualizations of the Role Development Process: Recognizing the Role Development Process}

This second section presents the role development process as described by the stakeholders. All agree that this process must include appropriate stakeholders; it must not be viewed as a "top-down" initiative.

The dimension "Recognizing the role development process" which describes participants' conceptualizations of the role development process is examined in this section. Six themes, elaborating further on this dimension are identified and presented below. These are:

- view as a new role with its four sub-themes;

- attend to group process;

- enlist support from ER administrators and stakeholders;

- ensure candidates are autonomous clinical experts with strong interpersonal skills; and 
- recognize that this role will change the current nurse/physician dynamics with its three sub-themes.

Participants, including administrators, had much to say about how the role should be developed, what should be considered and who should be involved in this process. Administrators had more to say about the role development process than they did about the role itself and NP functions. Participants emphasized the process, drawing from other experiences to demonstrate the importance of involving stakeholders in determining role expectations. They were especially concerned that this role be officially developed, respecting law with the support of governing bodies, rather than using "local recipes". As Quebec is not a leader in the development of NP roles, there is a sense that obtaining national or provincial recognition to ensure that the team benefits from other experts' experience and wisdom.

"I don't think it should be a local recipe... I think it should be a national approach, if not provincial then. It also needs to be well recognized by the population that they may be seeing a nurse practitioner... (P3: 261-267)."

"Maybe we should see what was done elsewhere to be able to see which function the NP should do... (N2: 67-69)."

"...we're maybe behind, but we have a lot to learn from them (other provinces/countries) and see what worked, what didn't work, and learn from that to make sure that our process goes through nicely (N3: 577-580)." 


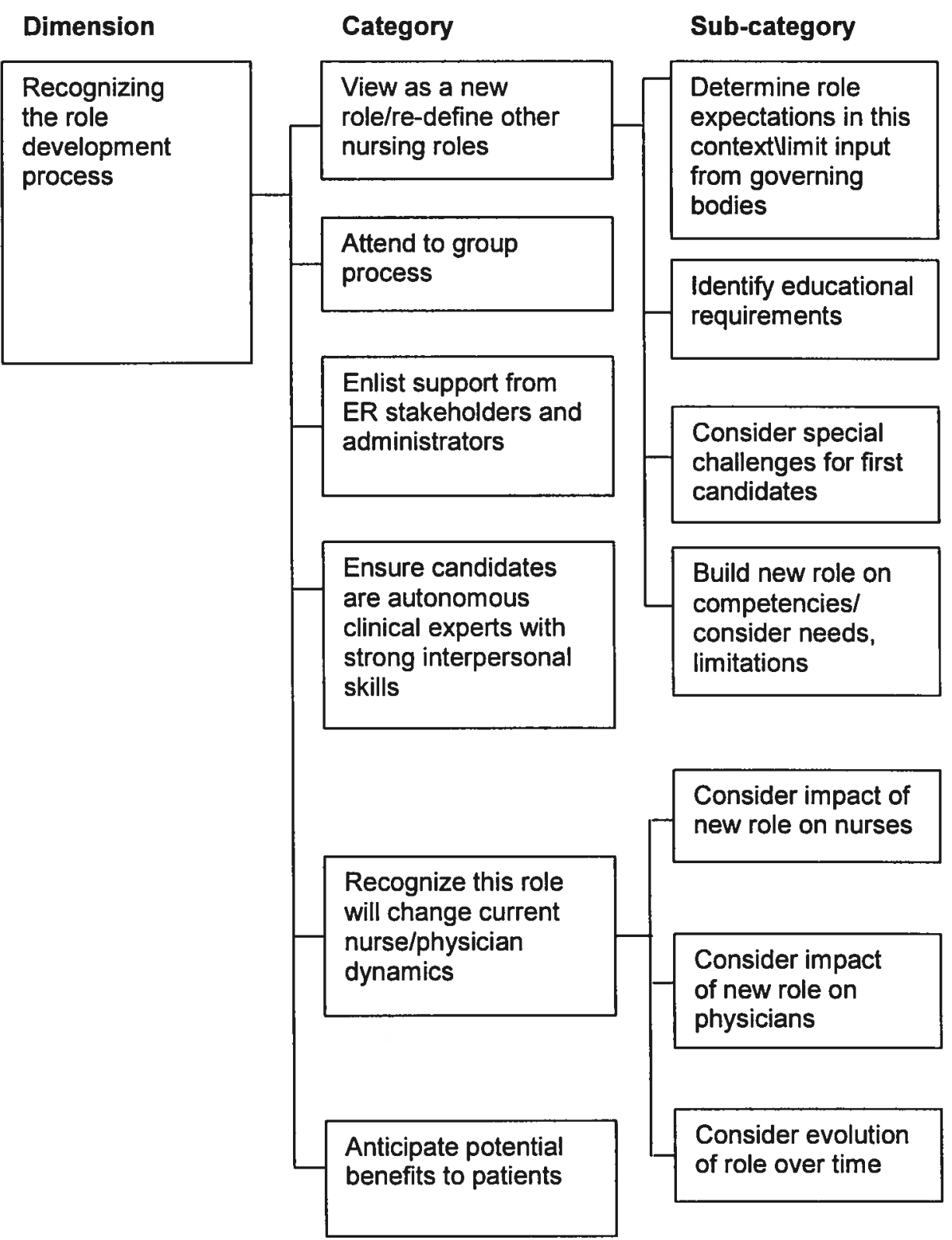

Figure 2 - Conceptualizations of Role Development Process 


\subsubsection{View as a New Role/Redefine Other Nurses' Roles}

Participants emphasized that the NP role be viewed, as a new role in the health system, for it is a huge investment at both provincial and institutional levels. Many stated that attention must also be focused on how the introduction of this role will change working dynamics and management among staff nurses, assistant head nurses, and clinical nurse specialists in the ER. Clarifying all these roles is essential to ensuring buy-in from all nurses. Also raised were questions on how an NP role differs from a CNS role: in particular, these two roles need definition in order to maintain a respective focus for each.

"...it might mean that there is a decision or a conscious decision of transfer of responsibilities from the assistant head nurses (AHN) to the nurse practitioners maybe training and education functions... I think a right balance will have to be struck, and I think it's partly institutional, I think it is partly what the Assistant Head Nurses want and partly what the NPs want to do (P2: 154-163)."

"Here (ER) the CNS has a hybrid role between an educator and advanced practice. The NP has a focus on kids that come to ER and the CNS has a focus on nurses who take care of the kids in ER. So where there is overlap... the CNS has to get along with the NP... there must be negotiation (N1: 561-572)."

"... if you conceptualize the role as a replacement (versus a new role), then once you have more residents or physicians and these roles disappear, that is a shame because you're 
investing, not just we, the institution, the university, the province.... so it is important, way at the beginning, when an institution or province is conceptualizing this kind of thing that it is viewed as a new role in the health care system (A1: 279-289)."

\subsubsection{Determine stakeholder role expectations/limit input from governing bodies}

Participants were very forthcoming on the importance of this new role being developed primarily by ER stakeholders, with other selected consultants, and most importantly, limiting the role of other governing bodies such as the Ordre des Infirmières et infirmiers du Québec (OIIQ) and le Collège des médecins du Québec. Administrators, physicians and nurse participants agreed that the newly developed role must work for the ER and all its stakeholders. Stakeholders with deep comprehension of the ER context must have input, ensuring that the role meets the particular needs and quality standards they are responsible for implementing every day.

"By whom? I think to some degree the Ministry should be out of it as much as possible. This ministry, the bottom line is money, that's the end-point. I don't think the quality of care is such a priority for the ministry. Collège des Médecins, l'Ordre des infirmières, FIIQ, and the population should have a representative... (P3: 272-278)."

"Mainly the people who are on the department, people who will be working closely with them (NP). Because if the decisions are taken by people who are not on the floor, they 
have more of a global view, which is fine, but I don't think that allows for the daily difficulties which people on the department have to deal with (N3: 268-273)."

"I really don't think there is a magic recipe. I think it is a question of the team saying 'we are going to be introducing this person, why are we introducing her, what are the needs here, what needs are we trying to address'. I think the end of this, it must be very clear to everyone that this is a process, people need to understand this. And, it is also a question of the comfort level of your practitioners... (A3: 257-264)."

"I think the questions may be the same for all centers, probably, but the answers may be different for different centers, so I think a committee needs to work on this and decide how this would work best in their center (P1: 245-249)."

\subsubsection{Educational requirements}

Although some participants were unclear on what educational requirements are stipulated by law, they were clear that both the level of experience and education must be determined before role implementation. Administrators did not comment on this aspect. It may be that the nurses and administrators were aware of these requirements, but physicians were not.

"So the nurse would be trained at the Master's level, but is it like a program in Ottawa (primary care) or the US? But for the first cohort, do you want them to be trained at the regular 
program and then you bring them in... or do you want to start the program from scratch at McGill? (N1: 372-380)."

"... I think you must decide what the acceptance requirements are, the number of years of experience needed, are they students coming right out of nursing, or do they have to do further training as a nurse practitioner? (P1: 218-223)."

\subsubsection{Consider special challenges for the first candidates}

Participants had advice and experience to share in anticipation of particular challenges facing the first candidates filling this role. They felt it vital that those developing this role in the future foresee this aspect and plan accordingly to ensure success for both the role and its first candidates or "pioneers". Given that this is a new role in the ER and relatively new to the province and the required investment and planning to operationalize, there was a sense that experience from developing other roles could be used in this context as well.

"Well, I think we need to be very careful, obviously with any program, that your first three candidates are superb. You have to meet a standard that is probably higher than subsequent ones because they've got to better than what they are replacing and demonstrate really high, high value. And so, I think your first three candidates are critical (P1: 430-437)."

"Unfortunately, these first pioneers always end up in contexts where there's conflict... (N3: 497-498)." 
"So, in the system, people have a hard time initially adjusting to it, so you need a lot of, I guess guidance, and group effort in starting off on the right foot describing what the role is, what it isn't, making that clear to everybody, then making sure that you have the right people to start off in those pivotal roles especially to start with, because you want someone who's going to make it work, make it successful (A1: 41-50)."

\subsubsection{Build new role on competencies/consider needs, limitations}

Participants were adamant that this new role should be based on already existent competencies, meeting specific needs identified in the ER. The identification of needs is particularly important to developing a role that properly addresses priorities. Given that this is a new role, the idea of maximizing something which is already a strength, where there are additional needs already identified makes sense. Some specific protocols, which could be implemented in the surgical emergency, fit these criteria. For example, in an earlier discussion, nurses described initiating assessments and deciding if a child needs an $\mathrm{x}$-ray following an injury involving the bones in the forearm. Some participants felt that the nurses have a lot of these competencies, and that maximizing these makes sense, particularly if long waits might be avoided.

"I think it is a question of the team saying 'we are going to be introducing this person, why are we introducing her, what are the needs here, what needs are we trying to address' (A1: 257-264)."

"I think there needs to be a committee.... to sit down and say what our needs are, who currently does what? Is that the best 
use of that person's time? Are there areas others are involved in and have the time to do and make a career of that and are empty... (P1: 228-234)."

"I do not think we want to add programs, I think we want to do what we do and do it well... Our goal is not to add a program of care, it is to improve the care that we give (P1: 384-389)."

"We have something challenging here, and I think it's the surgical side of the ER. How about having an NP there concentrating on building this specialty? (N1: 43-49)."

This theme demonstrates the importance of viewing the new role as determined by stakeholders and built on the competencies and the needs identified by them. In addition, educational requirements and special considerations for the first candidates filling the role should be considered.

\subsubsection{Attend to Group Process}

The second theme detailing this dimension is called "attend to group process". This theme had unanimous reaction among all participants, the message being that whoever develops this role in the future must absolutely proceed with ER stakeholders as consultants. Participants indicated with consensus that this role must be developed by a team of ER nurses and physicians, and that while other consultants may be used for particular issues, the framework and decisions must be made by full time ER physicians, ER nurses and nurses in leadership positions. Attention must be focused on the process this group is trying to achieve: not only "who", but also "how". 
"...when we introduce these new roles we are focusing on the operational things... like a safety component, do we have the staff, the money and whatever; and the whole other aspect of it, you know we are changing our practice here, ok. We don't spend enough time on that. Our objective is to spend more time on that, what will do us in is not the nuts and bolts, but the softer stuff that we are needed to achieve...(A3: 351-366)."

"Who should be involved? I think all of the (ER) team. Like the director of the emergency for the medical point of view and maybe a few of their full-time physicians, likely that is important. Also, the head nurse should be involved; just to make sure the relationship goes well with the physicians. I would involve the clinical nurse specialist for the teaching part... (N2: 77-82)."

"I see it as a committee; I would say management part is the head nurse, the assistant head nurse, the clinician (CNS)... I would go as far as saying maybe input from regular nurses and physicians to ensure input from different levels... maybe an NP from somewhere else in the hospital (N4: 170-182)."

This theme illustrates once again the importance of the ER stakeholder team as key participants working together to define this role. They do not see such a role being built by outside stakeholders such as governing bodies or administrators. 


\subsubsection{Enlist Support from ER Stakeholders and Hospital} Administrators

Participants of all three groups described at length the need for appropriate support for this new role. In addition to eliciting support from within the unit, much feedback was offered on critical support within the larger environment of the hospital itself. The importance of anticipating problems, proactive attention to issues before escalation, and somebody present tracking likely issues was underscored. In addition, this theme was dominated by a need to recruit other partners at different levels to reinforce goals and use various strategies and interventions to attain them.

"...because of one to one contacts and supports from what I call the core team, that is monitoring the introduction of this new role. Different strategies are used... that head nurse contacts the head nurse of the unit involved... Sometimes medicine to medicine, physician to physician, they have the same language, understanding (A1: 113-127)."

"...I think it is on the medical side that you need (support). Then the role will be well accepted. The people in charge of residents have to be involved with the NP (planning) (N1: 360-367)."

"I think the way it is introduced is very important, the role clarity has to be really there. Good support for the individual has to be in place. They just cannot be put there and say go to it! You are going to have to have a good reporting structure, or if they have problems they can be solved easily, 
stepping in to anticipate problems and be very pro-active (P1: 442-448)."

This theme illustrates stakeholders' conceptualizations as central in the decision-making process, with support expressed by hospital administrators and other key hospital stakeholders.

\subsubsection{Ensure Candidates are Autonomous Clinical Experts with Strong Inter-Personal Skills}

While participants were very articulate on ensuring a process with ample support for these new candidates, great emphasis was also placed on the quality candidates and the personal characteristics important to success. This theme outlines participants' conceptualizations of the personal characteristics and skills individuals must possess or acquire in order to successfully integrate this advanced practice role. Such characteristics must not to be neglected or underestimated in role planning. The conceptualizations reflect a vision of leadership required for this advanced practice role.

"And sometimes we have a tendency to pick more the academic stuff and the knowledge, which people can acquire. It's hard to ask a twenty some or thirty some person to change their personality or their leadership skills or their conflict resolution and I think those are really key things to look at (A3: 378-384)."

"...a tremendous amount of importance the people who are in those roles at the time. How much or are they known by other 
individuals outside. What is their reputation? So much of it comes down to this and it isn't really discussed (A3: 139-141)."

"... they need to be professionals, they need good communication skills, they need to be up to date scientifically, they need to be medical experts in the subjects they talk about. They need to be able to multi task... We are talking about an individual who likes a diverse body of knowledge as opposed to someone who likes to specialize in a very small area, self starter, independent... (P1: 36-45)."

"So, the NP has to be able to make choices, stay focused, be able to analyze, use her critical thinking... (N1: 103-106)."

This theme expresses stakeholders' conceptualizations of the NP as having specific and essential leadership skills. Stakeholders from all three groups expressed similar preoccupations with these characteristics.

\subsubsection{Recognize this Role Will Change the Current Nurse/ Physician Dynamics}

This theme, along with its three sub-themes, reflects an expected shift in dynamics with the introduction of the role, as well as an expectation among participants that this angle be anticipated and considered. The recorded conceptualizations indicate that a new dynamic needs to be defined, that this must be done in a way respectful to all stakeholders, and that this process be recognized. Defining the role may be critical, but ensuing relational adjustments require equal consideration and must not be overlooked. 
"There will always be individuals who either didn't agree with the position in the first place, or you know, you get a couple of these people. But usually that wanes, that disappears over time. So the dynamic changes over time to really create a space, if you will for that person and a new relationship or a new way to function (A1: 146-151)."

"I mean people have to adapt to change, and if change equals better care for patients, I think in general people ah... (will adapt)... I think it is more the way it's implemented than the role itself that would be a problem. It has to be done in a manner that does not rush anyone, that does not put them in a defensive position (N3: 238-242)."

\subsubsection{Consider impact on nurses}

Recognizing the importance of a change of dynamics, this sub-theme addresses consideration of the impact this role will have on ER staff nurses, Assistant Head Nurses, and the Clinical Nurse Specialist. This role will alter how nurses and physicians work together, how nurses work together, the type of care nurses will give, and who delivers it. This will necessarily change the dynamics of the nursing team. Participants' conceptualizations reflect an awareness of this and the essential nature of considering impact on nurses as part of the role development process. Many unanswered questions are voiced, pertaining particularly to nurses.

"But with the nurses, the only thing I can see just knowing that the nurse (NP) has new responsibilities will have an impact on the team. Just accepting the role, not because she (NP) will interfere with the (staff) nurses' role... but because 
there are some changes sometimes with new roles... maybe taking orders from the nurse (NP) to a nurse... and resistance from the (nursing) group (N2: 130-143)."

“...I wouldn't want to see a hierarchical role, I would want the regular (staff) nurse to have a major impact in the acute care (N4: 96-99)."

"Does she need to be there and have a clinician (CNS)? We have a clinician who is very good in teaching, in passing new information to the staff nurse.... So, how would the NP fit with the Clinician? I don't know... (N4: 88-93)."

"... it is often senior nurses who will be less supportive. There will be power struggles that will go on. Power games like "I won't take that order because you don't have that signed by a doctor, and you can't write orders (A2: 50-53)."

\subsubsection{Consider impact on physicians}

This second sub-theme explores particular considerations voiced by participants on the impact this role will have on physicians. Specifically, participants revealed conceptualizations of the role having the biggest impact on the physician group in terms of actual work. Because this role is largely seen as taking on some aspects traditionally performed by physicians, it was expressed that those feeling the greatest impact would be physicians and trainees.

"I see the difficult thing more for the physician. To me, the NP is more touching the 'physician like' work than the nurse. I 
don't think the NP will remove any work from the nurse. I think it is just an extension, so it's going to be the physician who will, to see what they will let go for the NP (N2: 70-75)."

"We (physicians) spend a lot of time doing that (following up lab results) It seems to be not an effective use of our salary...we should be using them (specialized skills) to the maximum, because that is what we are paid to do, to use those (specialized) skills (P1: 617-622)."

"Certainly, there will be a change in dynamics because you have medical students and residents in the ER.... But there can be a sense of competition or friction between them and the NP because there is a sense of the NP 'stealing their patients or their educational opportunity' (A2: 32-39)."

\subsubsection{Consider evolution of role over time}

The third and final sub-theme sheds light on participants' conceptualizations in relation to role evolution. While changing dynamics are important, so is the on-going change that comes with an evolving role. As evolution is by no means a static process, what seems pertinent at one point may be less significant at another juncture. Participants' stressed to others the magnitude of such change, how starting small is important and finally, how big the potential for evolution is.

"She should be able to always learn, and as a nurse, I don't always do (Categories) 4 and 5, so why should the NP? And depending where she is in her training and her capacity, she will graduate to take care of them (sicker patients) (N1: 146-151)." 
"So, I think you have to go slowly. If this involves doing this as a pilot project, and then increasing slowly from there, I think our experience in our setting would be (like) the NICU with NPs are a great example of how, through the years, their credibility and their development went through with this (approach) (N3: 483-488)."

"... but the NP, after experiencing the $\mathrm{MCH}$ and/or other ERs and understanding how we work, should have the ability to say 'We could do this better if...' So I think visioning the role of the NP would be appropriate. I would imagine that initially the role would be or seem a little restricted because it's brand new. And so somebody would have to have the ability to bring in information about other ERs or other people about why an NP could do more within a department (P2: 105-113)."

This theme illustrates the importance of recognizing the impact this role will have on both nurses and physicians. It will evolve with changing realities over time, significantly changing how these two groups deliver patient care. Such transitions must be managed so that stability and the quality of patient care are maintained.

\subsubsection{Anticipate Potential Benefits to Patients}

The final theme of this dimension reflects participants' preoccupation with the importance of anticipating the benefits this role could bring to patients. The notion of a clinical role to enhance the quality to patient care, and building this role on competencies was described in earlier themes. This theme expands on the notion of keeping the role centered on patient care and anticipating what benefits can be gained for patients. 
"Our leading problem from the patient's point of view is waiting time. That is a huge concern and if that can be relieved by facilitating care with very experienced people; good judgment, good communication skills... So they can help I think in that sense and maintain quality of care which is important (P1: 352-362)."

"I think the goal or the purpose of the NP is to give better care to the population in general in terms of approach and also the waiting time and the efficiency of the services... We do not need to have a physician to meet all the demands (P4: 343-355)."

\subsubsection{Conclusion}

This section has extensively described the stakeholders' conceptualizations of the role development process as requiring team-like collaborative effort and involvement by all stakeholders, using other consultants as necessary. Most importantly, they wish to have a strong voice in relation to the role development process, with limited input from governing bodies. All three groups of participants expressed views on the characteristics and skills required for this advanced practice role. There is little divergence in their conceptualizations of the role development process. The large amount of data in this section demonstrates the importance of this process for them. They also view this as a role that will evolve over time, significantly impacting how nurses and physicians work together in care delivery to pediatric ED patients.

It is important to note that administrators had more to say about the role development process than the NP role or the ED/legal context. This 
second section had more data than the previous and following sections. The quantity of material supplied by the administrators on this topic clearly demonstrates that they wish to have input in the process.

Administrators expressed less about particular populations the NP should work with, but had more experience with other advanced practice roles than the other participants. Hence, they had more to say about the role development process than the role itself or context.

The next section describes factors that favor and/or impede the conceptualizations of the NP role in the pediatric ER setting.

\subsection{ER Contextual Considerations and the Larger Legal Context: Organizational Barriers and Facilitators}

This third section describes the contextual considerations specific to the $\mathrm{ER}$ as well as the larger legal context in the province of Quebec. Participants, with the exception of hospital administrators, had limited understanding of the legal context and the position statements of the various governing bodies. This is important, as it demonstrates they have a good understanding of the ER context, but not of the larger context. These position statements and laws are important, as they will in part determine the scope of the role. The dimension "organizational barriers and facilitators" is explored her, with its three themes and corresponding sub-themes:

- consider potential barriers;

- consider facilitating factors; and

- consider current Quebec legal context. 


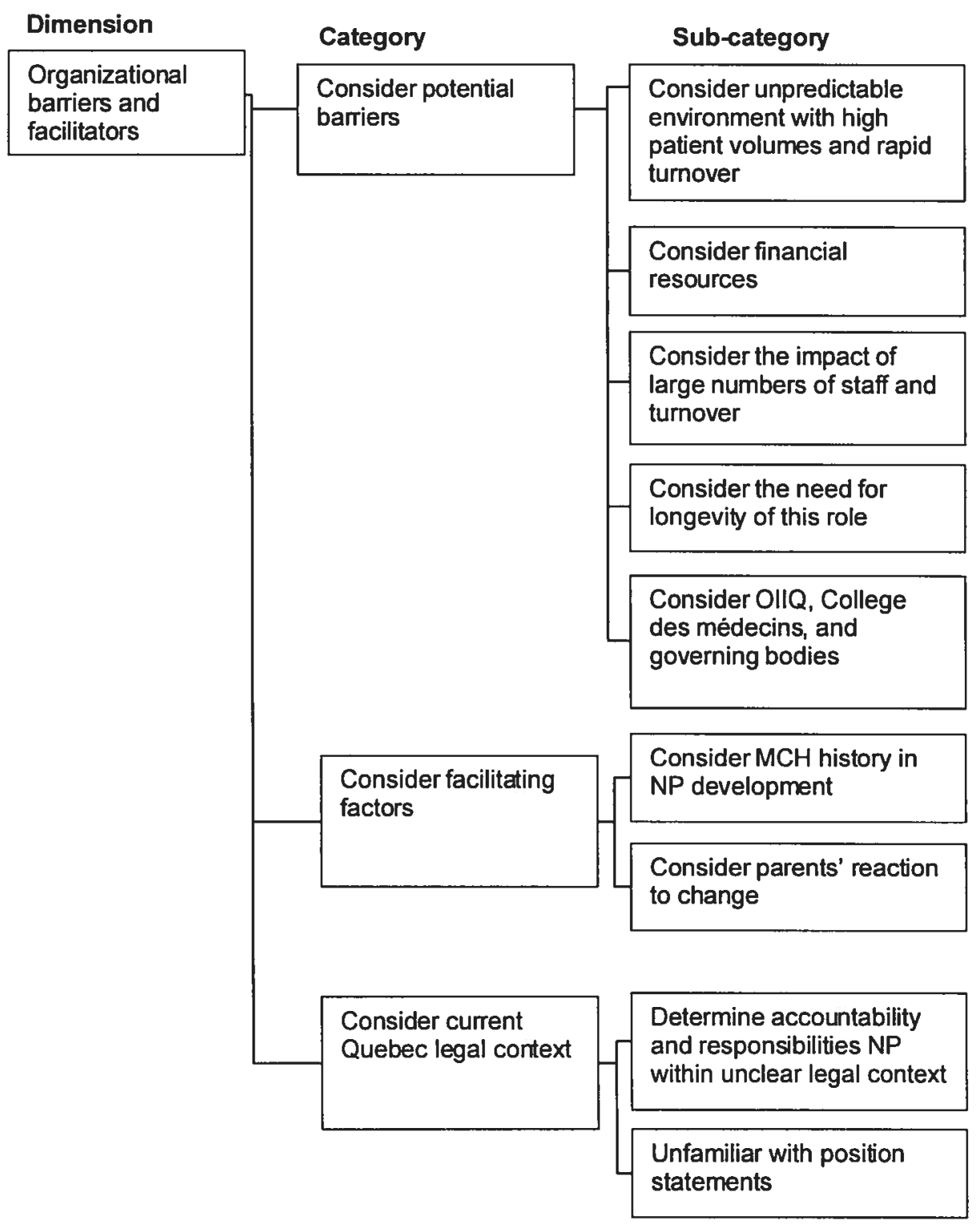

Figure 3 - ER Contextual Considerations/Legal Context 


\subsubsection{Consider Potential Barriers}

In this theme and five sub-themes, participants explore the potential barriers or factors impeding this role in the pediatric emergency context. The sub-themes shed light on these potential barriers; in some cases you will note that many of the participants expressed them as such, another participant may have seen the same contextual consideration as having a potential benefit. Administrators were very vocal, drawing on experiences in other areas where this role was implemented. Their conceptualizations reflect different impediments from different stakeholders at different points in the timeline following implementation, both within the institution and the province at large. The concerns of some participants were based more on theoretical possibilities than prior experience.

"... the barriers come from I guess the two traditional professions. Well, it starts from the traditional two professions are affected the most and that's the medical practitioners and then the nurses at the bedside... both of whom don't have a clear understanding of what this new, I call it hybrid role, is and along with a certain understanding of the role, comes a lot of perceptions of maybe what the role is or isn't (A1: 19-29)."

"There aren't really any institutional barriers because the nurse practitioner role is here at the (hospital). It is going to be workload; it's the University of McGill School of nursing and the Collège des médecins, that's where the problems are... (A2: 11, 24-27)." 
"I think it's not only an institutional barrier. If I go broader first, I think that Quebec is way behind on this issue of NPs. It's an entity that people have a lot of trouble understanding. It's been perceived as something very threatening by the group of omnipraticiens...(general practitioners) I think that unfortunately, it's been given a bad reputation before it's been given a chance (A3: 50-57)."

\subsubsection{Consider unpredictable environment with high patient volumes and rapid turnover}

This first sub-theme is one where both nurses and physicians contributed much, as it pertains directly to the ER context, their area of expertise. They mostly saw this unpredictable environment with high patient turnover as a difficulty particular to the ER, although one participant saw this as a good thing in terms of seeing enough volumes and variety as a plus guaranteeing a good "clientele" for the NP. The issue is pertinent in terms of determining which populations are appropriate for an NP to deliver care to, and with what level of autonomy. One participant pointed out that the pediatric ER context is one with a very low tolerance for medical errors, another important consideration for the role implementation.

"...this is where the emergency is difficult because it's not predictable. When you are somewhere in your role, your description is well identified, you know what to do, you do this at ten o'clock and whatever.... Here, you come here... you're not even sure if you're going to get out (P3: 406-415)." 
"What is clear about pediatric ER compared to adult ER, if you do an error in pediatrics, the parents will not forgive you. The likelihood that they will accept that this is an error which is acceptable is very low (P3: 443-447)."

\subsubsection{Consider financial resources}

The issue of financial resources was raised by all three participant groups. Finances are a global issue in health care; this is no exception. Administrators raised the issue of funding: the larger budget structure is not set up to accommodate the NP role. This touches both medicine and nursing. One shared financial concern was the critical issue of physician income and the importance of this being settled at the outset.

"And so, you don't want to take away income from physicians, yet you want to recognize that these nurses are contributing to the delivery of so called medical acts, so that is why funding must come as a new source, otherwise it gets perceived as taking away from physician's income or nurses' income (A1: 74-81)."

\subsubsection{Consider the impact of large numbers of staff and turnover}

This is also an area where concerns (including one very particular to the ER context) were mostly raised by physicians and nurses. This is a context where large groups of different professionals and support staff come together to provide service to large numbers of patients. This can be overwhelming and impersonal, with a resulting high turnover in staffing. This was identified as a potential barrier, which might make role implementation difficult because of inconsistency of medical staff or 
mentors, as well as impacting directly on the relationships between NPs and physicians, making trust and familiarity difficult.

" ... there is a core of these staff (physicians) emergency, stable people, it will be much easier to get used to each other, to find a place, have good exchange, have good integration... and to trust each other (P4: 261-274)."

"So it is easier if you are a small team and you know each other very well. Now when you have a lot of turnover, it takes longer to adapt, and maybe some people never will be able to adapt to that (P4: 318-323)."

\subsubsection{Consider the need for role longevity}

The importance of retaining NP candidates was seen as important, given the magnitude of the investment that role implementation would require. This role is seen as a career choice, not just a job, and the issue of addressing factors which might influence longevity was emphasized.

"Turnover in emergencies is pretty high in general for physicians. Will it be the same for the NP? If the turnover is the same, I don't think they will be able to be good nurse practitioners. I think it needs to be a career choice to be a NP... (P3: 379-383)."

"So it might be good to learn the fast-track stuff first because that is the easier fix, initially. But they should not be limited to that because that will get boring... I would hope we would 
expand that (fast track) frontier to start learning how to evaluate sicker kids... I think that is how you create more of a challenge to the job, and that is how you're going to keep people (A2: 149-162)."

\subsubsection{Consider the OIIQ, the collège des médecins, and other governing bodies}

This was an issue mostly raised by the administrators, again based on participants' experiences with previous NP role development. While they were clear that the role should be developed by ER stakeholders, they also expressed the importance of not alienating these governing bodies, of enlisting their help and/or support to eliminate barriers from them later in the process. Several barriers were raised by governing bodies, specifically the Collège des médecins, in relation to the NP role in Quebec. One participant had an interesting suggestion: strategies to ensure their collaboration or support of the Collège des médecins are used in the future. It was also pointed out that those implementing this new role need to ensure a rigorous process to demonstrate a strong commitment to safety and protecting the public, which is a central mandate of these governing bodies.

"So I think it is something that as we introduce we have to be conscious of helping them witness the impact, and so including them in how you introduce this. Not necessarily because you want them to make the decision, but politically keeping the larger network aware of your interest, your development in this... (A3: 280-286)." 
This first theme illustrates the importance of considering the barriers from both within and without the institution, including the legal context, and those from the governing bodies. The pediatric ED is one with particular challenges including high patient and staff volume and turnover. Additional constraints that bear consideration include limited financial resources.

\subsubsection{Consider Facilitating Factors}

The second theme of this dimension, along with its three sub-themes, was seen as equally important by the three participant groups. While they were conscious of elements considered as potential barriers, they also discussed at length facilitating elements and the importance of building on them. Particularly, despite its chaotic nature, this context is open to trying new things, and this role is a great way to demonstrating advanced nursing practice.

"I think it is also important to look at the shifting realities of who provides healthcare in Canada and NPs are a credible group that has competency and we know it has worked elsewhere (A3: 23-27)."

"The climate is good between physicians and nurses... we have a good relationship, that's one of the strengths of this place. I don't think introducing an NP would make a difference in the sense of making the relationship bad. I don't think so (N1: 292-300)."

"... we are in a university teaching hospital, and there's lots of opportunity to try new things, and I think that context would 
facilitate the implementation of a new role because we are always looking to improve the quality of care we are giving... we have a huge flow of patients, not enough people to take care of them... everyone agrees that there's something to be done there. (N3: 462-470)."

\subsubsection{Consider $\mathrm{MCH}$ history in NP development}

Participants of all three groups saw the history and experience their hospital has as pioneers in this province developing and instituting this role in other areas of the hospital as an important facilitating factor. These roles were instituted as pilot projects, and were very successfully designed and implemented based on unit needs. The experience generated from these pilot projects both internally and externally of the institution with various governing bodies was seen as facilitative. In addition, one participant voiced the importance of this institution's commitment to supporting innovation even in contexts where there are substantial external barriers, be they from the legal context or political from governing bodies. This was an important factor, not to be underestimated.

"Maybe the legislation doesn't back you (in those gray zones), but maybe the institution will because of the way it's functioning (N3: 534-536)."

"We also have the benefit of having NPs here in our own institution... with a track record of success. Innovated here, to a large extent in Quebec, so we are building on success stories (A3: 68-72)." 


\subsubsection{Consider parents' reaction to change}

This issue of parents' reaction to change was viewed by most as a facilitating consideration. Many of the participants had a sense that parents would adapt well to this, that they expected parents to generally be in favor of this initiative. This has been the experience in other settings within the hospital, and in addition, there is an element in the culture of the institution where parents often come to the ER seeking advice/reassurance and are not necessarily insistent on seeing a physician per se.

"I think for them (parents), especially in an emergency department, we have to understand the state of minds parents come with... they have a problem, they need someone to help them. Beyond that, they're not really hung up on titles as much as we are. So I think most families will be receptive to it (A3: 173-179)."

"I think the public has started to understand and appreciate the nursing knowledge and the expertise nurses have in the health care system. And this would be a natural sort of transformation into a more formalized recognition of that expertise and knowledge (A1: 196-201)." 
4.3.2.3 Consider the NP role as an addition to current human resources

This sub-theme was emphasized by many of the stakeholders; participants were adamant that in this context, it is very important that this role be viewed as additional. Participants expressed conceptualizations of the emergency nurse practitioner, a complement to the current roles nurses and physicians currently occupy. In a context of consistently high demand for service, where there are less medical trainees each year, where the turnover of both medical and nursing staff is high, the emergency nurse practitioner was viewed as an addition, not a substitute, for other workers. In a context of instability, the development of a role which brings "calm to chaos" was expressed; a role which adds the possibility of "bridging gaps" and ensuring another solid player "extending the nurses' role" and ensuring more stability and quality.

"...we can't consider they have finite and endless resources of residents, so we need to manage that. We have a group of pediatricians who are community based, who work in the ER. But the ER can be quite daunting for some of those physicians, and I think there is a way of having a nurse practitioner whose skills are developed in a certain way to complement the presence of attendings who are more community based (A3: 37-48)."

"Well our (ER) context is excellent, with high volume of patients, inadequate number of nurses, inadequate number of physicians, inadequate number of technicians, respiratory technicians, lab technicians. There is a large volume that can be seen. Now that is only valuable if the NP is not going to take away from that group. If we are going to get an NP and 
lose two nurses to pay for that budget, that is not a fair tradeoff (P1: 336-346)."

"I can see the role of the NP being valid in the ER in this institution. I think for two major reasons; one is the large volume of kids coming through the department and the need for timely assessment and treatment plan; the second is there's consistently a lack of medical personnel, so I see the NP not replacing the physicians, but being complimentary to the physicians (A1: 1-8)."

This second theme illustrates the need to consider the facilitating factors present in the pediatric ED. Particularly, stakeholders wanted to underline the tradition and experience this hospital has in the development of this advanced practice role. All three groups of participants also believe parents of children seen in the pediatric ER would view this new role in a positive light, which would facilitate its introduction.

\subsubsection{Consider Quebec's Evolving Legal Context}

Nurses, physicians and administrators had little to say about the legal context, beyond the need for clarification and considering the ongoing evolution of the law. Their conceptualizations of the role seemed less influenced by the larger legal aspects than the ER context itself. Interestingly, beyond understanding the importance of clarification of key issues which must be obeyed or respected, this aspect raised little else than questions. 
The legal context will continue to evolve, and participants expressed that it may be wise to start small, permitting credibility to grow, and allowing the role to evolve with the law.

"...I think that Quebec is way behind on the issue of NPs... On the other hand, we have a group of physician specialists in Quebec who have been quite vocal, who have needs for NPs in the (specialty) areas. And I think that we have benefited from, in that respect is that in tertiary care settings, there's been an articulated need for the NPs. So, if you use that concept, the ER here is a tertiary center so I think it gives an opportunity to at least even talk about it here (A3: 51-67)."

\subsubsection{Determine levels of responsibility and accountability of the NP within an unclear legal context}

This theme, of determining precise level of responsibility and accountability in the eyes of the law, raised many questions and concerns. Beyond unfamiliarity with position statements, the law was seen as a major grey zone which needs clearing up for all involved. Clarification of NP responsibilities versus those of the physician, will determine at least in part how NPs work with physicians, and a specified level of autonomy. Recognizing that this is an ill-defined area, both physicians and nurses had questions on prescription, diagnosis, and discharge.

"... but if we have an NP program with provincial or national recognition, I think that is going to be one of the big decisions; if the NPs are able to diagnose and treat, physicians will prefer to stay out, that's my gut feeling. If they (the NP) 
cannot do that, then physicians will have to remain involved somehow either by direct supervision or by supervision a few hours later (P4: 496-504)."

"I overheard at one point some issues about discharging and admitting patients, and that becomes a bit of an issue... that's one of the grey zones, and we have to work within it. So yes you'll do things that technically you are not legislated for, but you sort of have to go through the pathway until the legislation realizes yes, this does make sense (N3: 527-536)."

\subsubsection{Unfamiliar with position statements}

This theme raises an interesting issue: most participants were unfamiliar with position statements of the governing bodies. Their conceptualizations of the role were therefore not determined by the position statements of the governing bodies, but rather by personal experiences with nursing, and the needs they, as stakeholders, had identified in a context.

"I cannot really base them (my views) on the position statements because I have not read them... I can only say that so many patients come to the Emergency department for reassurance, that everything is ok, and I think that is a skill that many nurses know better than physicians, and they currently do well; so I think it is an extension or responsibility really (P1: 503-511)." 
"I don't know much of it (the legal context). I am not going to pretend a lot. I know it has evolved to a stage where, I know Law 90 sort of expanded the nursing role (N3: 519-521)."

This final theme illustrates the finding that most stakeholders did not have a good grasp of the role's legal aspects or of governing bodies' position statements. This is especially interesting because it means that conceptualizations are not determined by these, but rather by other factors which may be unique to their context. It illustrates the importance of paying attention to these factors and including stakeholders in the role development process. Clearly, the legal context does in part determine the limitations and boundaries of the role, but within these boundaries there are a lot of issues the stakeholders wish to see addressed.

\subsection{Conclusion}

In conclusion, this third section describes participants' conceptualizations of the legal context and the ER contextual considerations. The most important finding here is that most participants were not familiar with either the current legal context or the position statements from the various governing bodies, which demonstrate that conceptualizations are not determined by these rules or guidelines. Most importantly, administrators (who had been involved in developing these roles in other contexts) had more to say in this section than the nurses and physicians. Nurses and physicians were not well informed about the law or what the current developments of this role are in the province. They appeared to have little consideration for or interest in the position statements or the larger legal context. This is significant because of the importance of ensuring that this role fits into larger health system goals as well as to avoid well-documented conflicts in post-implementation 
phases. In addition, the laws at the provincial level provide the legal framework, which in part define scope of practice.

Finally, all three groups described potential barriers for this role in this context especially related to unpredictable environment, scarce financial resources, large numbers of staff and resistance from governing bodies such as the Collège des médecins.

\subsection{Critical Synthesis of the Results}

The findings described in the previous three sections demonstrate stakeholders' conceptualizations of the emergency nurse practitioner role in the pediatric ED setting, as well as the role development process, and, in a limited way, the legal context and position statements of governing bodies.

The findings demonstrate that nurses and physicians were very forthcoming on the NP role and what type of care they would deliver to selected populations. They saw this as a largely clinical role, with the NP delivering care to different populations including non-acute populations with a clear diagnosis. They were also clear that the role could not be extended to include all populations, because the pediatric ED has such a diverse population. It would be difficult to expect the NP to be able to manage them all. Despite this being a primarily clinical role, participants had expectations that this expertise would be shared with other nurses, trainees and patients and families. Almost all stakeholders expressed this. They were also emphatic that research and administration responsibilities should be limited. Having said this, they expressed that given this is an advanced nursing practice role, they expect NPs to show 
some leadership in these two areas and participate as part of the team in specific ways.

Stakeholders also saw an important role with acutely ill populations whereby the pediatric emergency nurse practitioner would use her advanced practice skills to deliver specialized and complex care to predetermined, acutely ill patients, using protocols and guidelines. While the nurses expressed this as an "extension" of their current role, physicians described specific protocolized work that they wished to see done before they see the patient. The nurse participants saw this as an opportunity to use the knowledge and skill of the NP in a way that enables her/him to take on more responsibility. There is some divergence here between the vision of nurses and physicians. While the nurses' conceptualizations of this role support a strong nursing orientation, the physicians' conceptualizations were more oriented towards physician replacement or support. The physicians' expectations were expressed not so much as an extension of the nurses work, but rather as "bridging the gap" between the work of the staff nurse and the ED physicians. They expressed the need to delegate more to the emergency nurse practitioner, again for specific populations where they see homogeneity, and less risk for error, and more possibility for standard interventions. They did not see an NP performing very specialized procedures such as endo-tracheal intubations and chest tube placement in critically ill patients.

The findings also illustrate that multiple stakeholders conceive this role as a nurse/physician hybrid role (a role which changes the current boundaries between these two professions) that should be concentrated on specific populations. They see this new role beginning at triage, right 
from the start of the visit, thus extending the nurse's role and bridging the gap between what nurses and physicians now do.

Interestingly, stakeholders had more to say about the role development process than they did about the role itself. Multiple stakeholders expressed the importance of having multidisciplinary stakeholders working together to determine the boundaries of the role, and thus ensuring role clarity. They wanted the support of hospital administrators, but clearly wanted to be central in the decision making process. Most importantly, they wanted the input of the governing bodies to be limited in order to ensure the role meets the clinical needs of the pediatric ED context. They had expectations of a new role based on identified needs and competencies of the unit. They were also conscious that this new role would significantly change how nurses and physicians deliver care to patients, which requires close examination. Administrators had more to say about the role development process than they did about what the NP would do.

Finally, they wanted potential barriers and facilitating factors of the pediatric ED to be considered. While many of these barriers exist in other settings, pediatric EDs have particular challenges that are unique to them, and these need to be considered. Participants had very little knowledge about the position statements and the legal context in Quebec. Administrators had more to say about this than any of the other stakeholders, thus providing important data about their previous experiences in developing these roles in other contexts. Their conceptualizations were not based on these rules and regulations, but rather on the clinical experience in the pediatric ED context. This is significant in that it supports Hilbert's (1981) work; viewing role is an 
organizing concept for shared conceptualizations used to maintain the stability of social interaction.

In conclusion, commonalities exist among different groups of stakeholders; the principle areas of agreement for the NP role were that this is a largely clinical advanced practice nursing role. Participants agreed that the emergency nurse practitioner should focus on both stable (non-acute) populations with a clear diagnosis and acutely ill patients requiring advanced procedures. Both types of care would be initiated by the emergency nurse practitioner using pre-determined protocols. Stakeholders concurred that they do not see a role for the emergency nurse practitioner with critically ill patients.

They agreed that this is a new role that reflects nurse/physician hybrid responsibilities. They were also united in expressing that the functions, responsibilities, and boundaries for this role must be very clear in order to avoid confusion and chaos.

With many of the participants in favor of an NP limiting work to specific populations, the question of the degree of autonomy with those selected populations arises. Participants, including nurses, physicians and administrators saw the need for this question to be addressed, not only in relation to what the law stipulates, but also in terms of their conceptualizations. Many participants did not have a clear sense of the law, but perceived that the question of responsibility needs to be discussed and defined. It is unclear who has ultimate responsibility. They saw the NP working alongside the physician, consulting as necessary, maximizing efficiency, yet respecting the law. They agreed that teaching and mentoring is important, and that research 
responsibilities must be minimized to ensure that the role retains its clinical focus.

In terms of the role development process, stakeholders unanimously expressed that this is a group process: while they require support from other stakeholders and hospital administrators, a team of ER nurses and physicians should develop this role. The role of governing bodies must be considered, but those closest to patients should make the decisions. It is significant to note that all groups had more to say about the importance of the role development process than they did about the role itself (what the NP should be doing).

Finally, there was agreement on particular contextual factors that might impede or favour the role, including: the unpredictable nature of the ER, high turnover of both patients and staff, and family perceptions of this role. They also were largely unfamiliar with the legal context and the position statements of the governing bodies.

There were few areas on which stakeholders disagreed or expressed diverging opinions. In terms of the role itself, a point of divergence was on how physicians versus nurses view the role. Physicians favoured NPs initiating treatment for selected populations using specific protocols or guidelines. Nurses, however, saw this role more as an extension of their current role, bridging gaps between the roles of nurse and physician. Physicians presented more precise examples of populations and procedures than the nurses. The nurses expressed the role conceptually rather than citing specific examples. They required more prompts to give specific examples of populations or processes. Administrators expressed less about particular populations the NP should work with, but had more experience with other advanced practice 
roles than the other participants. Hence, they had more to say about the role development process than the role itself or context. 
CHAPTER 5

DISCUSSION 


\section{DISCUSSION}

This final chapter revisits the selected methodology and strengths and limitations of this study. The scientific contribution and social and professional pertinence of this study are also discussed. In closing, recommendations are made for future research and nursing practice.

\subsection{Pertinence and Contribution to Nursing Knowledge}

The pertinence of this study lies in its contribution to both theoretical and applicable knowledge to the development of the NP role in the planning stages of the pediatric ED. It contributes to our knowledge of the pediatric ER stakeholders' conceptualizations of the emergency nurse practitioner role, the role development process, and the factors they believe will influence its implementation. There are implications for role development that emerge from this study: while the study's findings will most certainly be of value to developing this role in the institution that was studied, it also contributes to the theoretical knowledge for role development of an advanced practice role.

The analysis supports the view that the development of this role is not determined by rules or position statements. While the broader legal, professional considerations must be taken into account, clearly the stakeholders are more concerned with the local environment and the specific patient care needs they want to see addressed by this advanced practice role. It also demonstrates the discrepancy between what these stakeholders are saying about the nature of the role and the role development process, and what is reported in the literature. All the stakeholders expressed that they want very limited input from governing 
bodies and the overwhelming majority of them know very little about the position statements of these governing bodies. Therefore, although they are in a very good position (at the local level) to design the new role, they must understand its broader legal context in order to ensure it is patient-centered and congruent with health system needs. Stakeholder input is important, but not to exclusion of broader contextual considerations.

To determine the value of findings reported in the previous chapter, we must re-examine the methodology selected for this research project. The aim of this study was to identify stakeholders' conceptualizations of the planning stages of the pediatric emergency nurse practitioner role, as well as factors influencing its development. Using purposeful sampling, data was collected to elucidate this phenomenon. Analysis focused on coding and categorizing data, as described for grounded theory (Strauss \& Corbin, 1990). No commitment was made to theory development, as the phenomenon under study was not a process.

Findings described in the previous chapter and discussed in the next section demonstrate that this methodology permitted the study to confirm existing research documented in literature, and to identify new findings contributing to nursing knowledge. This process clarified stakeholders' conceptualizations of the planning phase for the nurse practitioner role in the pediatric emergency department, in addition to identifying favorable factors and impediments. The study's main contribution to nursing knowledge lies in clarifying:

- stakeholders' conceptualizations in the planning phase of the emergency nurse practitioner role in this pediatric ER; 
- the conceptualizations of the role development process;

- and the unique context of the pediatric ER.

\subsection{Conceptualizations of the NP Role}

Stakeholders' conceptualizations are critical to successful development of a complex professional role. Professional role development is an ongoing, dynamic process, which can be conceptualized as beginning with a planning phase.

A thorough literature search revealed both clinical (anecdotal) and research descriptions of NP roles. However, none described the stakeholders' conceptualizations in the planning phase of the emergency nurse practitioner role development. The development of various advanced practice nursing roles, including the nurse practitioner role, has been studied by a number of authors focusing on the postimplementation phases (Hamric et al, 2005; Woods, 1998; Lloyd Jones, 2005). Once again, it was important to note that none addressed the pediatric ER specifically; nor did they describe the planning phase of role development.

This study demonstrated that stakeholders, specifically nurses and physicians, conceptualized the emergency nurse practitioner in their context as a nurse/physician hybrid role, which extends the current nurses' role at triage. They described the emergency nurse practitioner as having a largely clinical role with a variety of specific populations (for example: fast track patients with a clear diagnosis), as well as having a number of sub-roles, including teacher/mentor, limited administrative and research responsibilities, and following up pre-determined populations. 
However, role functions must be delineated and well communicated to all stakeholders; if one is to ensure that the role is viewed an advanced practice nursing role with such functions visible and valued, rather than a physician replacement role. Failing to plan for this will result in well known barriers to educational and research activities due to competing clinical and medical demands (Bryant-Lukosius et al, 2004).

The stakeholders had expectations that NPs would bridge the gaps between nurse and physician practice in this ER, by working as part of the team, initiating treatment for physicians after triage for certain populations using protocols, and performing advanced procedures delivering complex care using protocols. While there was much consensus among stakeholders with respect to these aspects, there was one important discrepancy. Physicians articulated the need for the emergency nurse practitioner to initiate treatment (in their place), while nurses expressed the importance of not taking on the physician's work, but rather extending their role to better meet patients' needs. This is important to emphasize, because this new role will move the traditional boundaries of nursing practice and health traditional health care delivery. If this new advanced practice nursing role is to improve patient and health care system outcomes, it must be a complementary addition to the existing model rather than merely a shifting of responsibilities between health care providers (Bryant-Lukosius et al, 2004). It is critical that stakeholders ensure this is a well thought-out process rather than an arbitrary shift of responsibilities.

Stakeholders conceptualized this role as one limited to specific populations; they did not expect the NP to be involved in critical care or consults, but rather with stable and acutely ill populations. Most importantly, they emphasized the significance of determining role 
responsibilities. Autonomy, independence and ultimate legal responsibility for the patient must be made clear.

Hamric et al (1989; in Hamric et al, 2005) studied the development of the Clinical Nurse Specialist (CNS) role extensively. She described three "negative phases" related to the congruence of personal and organizational goals and expectations, during later phases of role integration. These three states, characterized as negative and unproductive, require role clarification, reviewed the advanced practice goals in relation to those of the organization, and re-negotiation of role expectations. Lloyd Jones (2005) reviewed qualitative research studies, reporting barriers and facilitators to the development of advanced practice roles mostly in the UK. This author's synthesis demonstrated that within reported administrative and organizational issues, role definitions and expectations were among the most critical factors identified (favoring or hindering advanced practice roles after implementation).

Both Hamric et al (2005) and Lloyd Jones' (2005) work overlooked the planning phase for role development. This study significantly provides stakeholders' conceptualizations in the planning phases of the role development process. The organization's expectations of the NP role are at least in part determined by a variety of stakeholders including those at both administrative and service levels. Ensuring clarity of these role expectations during the planning phase, at the administrative and service level, is essential to minimizing conflict and other negative effects that may impede the development of the role or later lead to undue turnover. 


\subsection{Conceptualizations of the NP Role Development Process}

This study described a number of stakeholders' conceptualizations of the pediatric emergency nurse practitioner, limited to those at the organizational and service level during the planning phase. Stakeholders conceptualized building the new role on strengths and competencies, considering the needs and limitations of the service and the organization. They expected the role to evolve over time, as needs changed, thus confirming the work of Hravnak (1998; in Hamric et al, 2005). This author conceptualizes scope of practice of acute care nursing practitioners (ACP) as determined at five different levels, including the institutional level based on needs and vision; and at the service level, collaboratively derived between the advanced nursing practitioner and the physician. She noted that this evolving advanced practice role must be based on the evolving needs of the population, the organization, work practices and service needs.

Most importantly, stakeholders unanimously expressed that role expectations must be determined in this context, with limited input from governing bodies. They saw this as a group process, with key stakeholders such as ER physicians, nurses, the Medical Director and the Head Nurse, and others making decisions together in determining role expectations, with the support of other ED stakeholders and hospital administrators. They conceptualized using a recognized process, learning from others who have implemented such roles before. They viewed this role as new, requiring other nursing roles within the unit to be re-defined. They also agreed that this new role would change 
current nurse/physician dynamics. Nurses and physicians alike have indicated that the impact on each respective role must be considered.

Brykczynski's interpretation of various role concepts developed (Hardy, 1988; and Schumacher, 1994; in Hamric et al, 2005) in the context of professional role issues, and Lloyd Jones' (2005) meta-analysis and synthesis of role development of advanced practice roles, highlight a number of important considerations including role ambiguity, role incongruity and role conflict. These concepts are discussed individually, incorporating the study's important contributions in the planning phase of the emergency nurse practitioner role.

\subsubsection{Role Ambiguity}

Brykczynski (2005) explains that role ambiguity develops when there are unclear expectations, diffuse responsibilities, and uncertainty about subroles after implementation. This is especially relevant in evolving advanced nursing practice roles.

The current study's findings described a number of role functions and role development issues that stakeholders view as critical before implementation. These included determining independence, autonomy and ultimate legal responsibility for the patient; clarifying NP responsibilities; developing the role using stakeholder conceptualizations; and limiting input from governing bodies. The study also showed that stakeholders view the pediatric emergency nurse practitioner as a member of the multi-disciplinary team. These findings were congruent with Brykczynski's (2005) interpretation of conflicts and difficulties which arise (post-implementation) when role functions are not clarified for all stakeholders. The study's contribution to the concept role ambiguity lay 
in the description of stakeholders' conceptualizations of the pediatric emergency nurse practitioner role. It also demonstrated the importance of considering these stakeholders' conceptualizations in the planning phases to avoid or at least minimize post-implementation role ambiguity.

Successful development of an advanced practice role must incorporate major stakeholders' conceptualizations in order to ensure stable social interaction. However, this study indicates that the stakeholders in this situation believe that this role should not be based on external rules or position statements (by governing bodies). They believe that they should have an important part in determining the nature of the role as well as the role development process. They strongly advocated for a minimal presence from external governing bodies, focusing especially on the need to tailor the role to the needs of the pediatric ER context.

However, the NP role is in part determined by the laws of this province, and as this legal context evolves, these external factors will have implications on the development and evolution of the role at the organizational level. Therefore, in order to have a role which meets the needs of the pediatric ER at the organizational level, stakeholders must consider not only factors at their level, but also those at the provincial level. While they have made it clear they do not wish to be constrained by the factors in the larger (provincial) context, they must consider them in order to ensure they plan an effective role. Failing to assess the conditions at the local, government, and health care system levels, as well as factors related to advanced practice nursing will have major implications on the effectiveness and legitimacy of the role (BryantLukosius et al, 2004). This failure could also lead to barriers later in the process (at the health system level) such as the advanced practice nurses' competency being questioned due to variable educational 
preparation. Another potential example is physicians' resistance to recognizing and endorsing these roles due to failure to address reimbursement issues and physician income loss.

At the local level, barriers include lack of resources for advanced practice nurses and role conflicts. These illustrate the need for strong administrative support at the local level to promote role autonomy, satisfaction, clarity and innovation.

\subsubsection{Role Incongruity}

Brykczynski's (2005) interpretation of role incongruity was that of intrarole conflict, described as developing from two sources. The first stems from incompatibility between skills and obligations; the second from personal values and expected role behaviors.

The current study's findings demonstrate stakeholders' conceptualizations of this role as primarily clinical, with specific populations and limited teaching and research responsibilities. Stakeholders in this pediatric ER had conceptualizations of this nurse practitioner role during the planning phase that require consideration before implementation if such incompatibles are to be avoided or minimized. The study did not include data from NPs themselves, another stakeholder who may not be part of the planning process. However, it seems important that this data be obtained and clarified before implementation, to prevent role incongruity during post-implementation phases. 


\subsubsection{Role Conflict}

Role conflict develops when unclear expectations are perceived as contradictory or exclusive to a group (i.e., for physicians or trainees). Brykczynski's (2005) interpretation of this concept includes both intraprofessional and inter-professional role conflict. Conflicts occurred in clinical settings among different advanced practice nurses and also with staff nurses when roles were poorly defined and understood, and priorities differentiated. Disparities and inadequate communication between advanced practice nurses and staff nurses can create major difficulties.

The current study's findings demonstrates stakeholders' preoccupation with the impact of the new NP role on both physicians and nurses. The stakeholders' conceptualizations were that this new NP role needed to be viewed as changing how nurses and physicians work together. In addition, other nursing roles must be redefined to ensure clarity and future cohesion among members of this professional group.

Brykczynski (2005; Woods, 1999) interpreted inter-professional role conflict as being most common between physicians and advanced practice nurses. Most conflicts revolved around perceived economic threat (competition), established hierarchies, inexperience working together and competition for training opportunities. These serious issues overshadowed the complementary nature of these two professional groups, and may have compromised collaboration required to ensure the sharing of a broad spectrum of knowledge that no single professional group was able to provide. 
Provision of inter-disciplinary activities and administrative support are two ways to promote collaboration between these two groups. This study's findings demonstrate that all three-stakeholder groups share these concerns, and identified these issues as needing identification in the planning stage of this process. Specifically, their conceptualizations included clearly addressing what monies are used to fund which activities, who is to have ultimate legal responsibility for patients, and training opportunities for medical trainees. It is essential to discuss these issues early in the planning process. In the absence of planning for these important considerations, support and acceptance of the role among physicians, nurses and others is threatened (Bryant-Lukosius et al, 2004).

Most importantly, if this role is to advance nursing practice, it must be developed so that it complements existing roles rather than competing with them. Specifically, it must be based on health care system needs rather than physician replacement or support, and consider not only clinical (patients related activities), but also non-clinical activities (such as research) to foster innovative nursing practice associated to patient satisfaction and quality of care. In order for the nursing components of the role to be valued, they must be visible and supported (BryantLukosius et al, 2004).

\subsubsection{ER Contextual Considerations and the Larger Legal Context: Organizational Barriers and Facilitators}

An important contribution of this research is its rendering explicit potential organizational barriers and facilitating factors. Among the potential barriers of the ER environment, stakeholders were concerned about high volumes and turnover of both patients and staff; the need to 
consider financial resources and clarify where these monies would come from; the need to consider factors influencing longevity of the role; and reflection on resistance or other potential barriers from various governing bodies such as the Collège des Médecins.

The literature reports a number of factors inhibiting the role postimplementation including: lack of understanding/unrealistic or unclear role expectations (Lloyd Jones, 2005; Nevidjon, 2005: in Hamric et al, 2005; Woods, 1999), lack of support and negative attitudes towards advanced practice from key stakeholders (Lloyd Jones, 2005; Nevidjon, 2005: in Hamric et al, 2005; Woods, 1999), resistance from other nurses, (Lloyd Jones, 2005; Nevidjon, 2005: in Hamric et al, 2005; Woods, 1999), lack of resources (Lloyd Jones, 2005; Tye \& Ross, 2000 Woods, 1999), and poor compensation (Woods, 1999). Loyd Jones (2005) noted there is a paucity of studies describing stakeholders' reports of both facilitators and barriers to advanced practice roles.

Among facilitating factors stakeholders described in this study are the strong leadership and expertise of the institution in advanced practice roles and that parents of this institution would likely view this new role as a positive change. In terms of the larger legal context, stakeholders have more questions than answers, the majority of them being unfamiliar with both the laws and position statements that provide the framework for this advanced practice role.

Other favorable factors described in the literature for the development of advanced practice roles included support by other staff members, other advanced practice nurses and administrators (Lloyd Jones, 2005; Woods, 1999). Lloyd Jones (2005) noted that the most important factors 
impacting the success of advanced practice roles relate to relationships with key personnel, role clarity and expectations.

The study details stakeholders' expectations of the role, the role development process and facilitators and barriers of the pediatric ER context. In addition, a number of stakeholders from the three groups interviewed emphasized the importance of developing the role with other key stakeholders, which suggests they value their support and input. This is critical to the development of the nurse practitioner role. Recognition of the different contexts and their special needs, the stakeholders' expectations of how the new advanced practice role will meet specific needs is of primary importance. The implementation of this role will be affected by the acceptance of all stakeholders including administrators, physicians and nurses. They must participate in planning and development in order to ensure role clarity, as well as successful integration in the local environment and the broader context. Lack of clarity and direction of role development occurs when patient and health system goals are not clearly defined. This in turn results in a lack of environmental conditions to support implementation and development (Bryant-Lukosius et al, 2004). .

Quebec has long lagged behind the US, UK, and the rest of Canada in developing the NP role. There has been substantial resistance to it, particularly in primary care areas of this province. Presently, there is support from the tertiary care sector, as the law provides for NP roles to be developed in certain specialty areas. Participants felt that this important element of the current legal context must be considered, as it is to their advantage that the ER is a specialty area. This is important because stakeholders who anticipate barriers also want to share potential areas of support and/or allies in this complex process. 
The exploration and description of the stakeholders' conceptualizations of the NP role in the pediatric ER coupled with a thorough review of the literature demonstrate the importance of exploring these in the planning phase of role development. The study's findings complement existing knowledge in the literature in relation to the development of other advanced practice roles.

\subsection{Strengths and Limitations of the Study}

In reviewing the research process with the study's supervisors, strengths and limitations were identified. Two such were both a strength and a limitation of the study. The first is that while the stakeholders were very knowledgeable about the pediatric ER context, their knowledge of the larger context was limited. This was helpful and difficult at the same time for the development of this role. Secondly, the researcher was the Head Nurse of the ED in question. She was very familiar and knowledgeable about the pediatric ER environment. She was also familiar with all the participants, one of who reported to her (the senior staff nurse). All the participants, including the physicians and administrators, also knew her. While these relationships could have affected the participants' disclosure of information, she had been absent from the site for a period of approximately 24 months, during which the interviews were carried out.

While the number of participants may be small, and only one pediatric ED was studied, the study followed procedure respecting purposeful sampling. The thesis supervisors judged the number of participants required for this study on the basis of their determination of adequate data density (Strauss and Corbin, 1990). However, the findings are not generalizable. 
Finally, while a number of stakeholders were interviewed, these stakeholders were limited to nurses, physicians and administrators. No parents, patients, NPs, or other important ER collaborators such as medical consultants, and allied health professionals were consulted; therefore the conceptualizations are limited to those groups that were studied.

A strength of this study is that it studied the emergency nurse practitioner role in the pediatric emergency setting; there is little reported in the literature on this role in this particular setting. It gives insight into the conceptualizations of the emergency nurse practitioner role in the pediatric ER, as well as the role development process, and the facilitating and impeding factors of this particular clinical specialty.

The most important strength of this study is that it extensively describes the stakeholders' conceptualizations of the planning process. It complements the work of other researchers such as Hamric et al (2005) who have extensively described role development of advanced practice roles in post-implementation phases but whose work does not describe the planning phase or the pre-implementation work required for successful implementation.

In addition it provides important information on the facilitating and impeding factors as described by a number of key stakeholders. There is a paucity of this type of data in the literature; therefore this study contributes to an identified gap in the literature. 


\subsection{Recommendations for Research and Nursing Practice}

The following section summarizes the recommendations for both research and nursing practice.

\subsubsection{Recommendations for Research}

The study's findings permit a better understanding the stakeholders' conceptualizations of the NP role in the pediatric ER. Eleven stakeholders were represented in this study, including physicians, nurses and hospital administrators.

These stakeholders represent important viewpoints; however, there are others whose views were not considered in this study. For example, patients and their families were not interviewed. Their conceptualizations are important, considering the magnitude of change this may represents for them. In addition, important ER collaborators such as medical consultants, and allied health professionals (i.e., pharmacists, respiratory technologists) were not included in this study. Finally, other nurse practitioners working in the hospital in question were not interviewed. Their experiences could have provided information on aspects that might have been better addressed in order to assist their integration as new practitioners. It is recommended that future research address other stakeholders to provide more clarity on these aspects.

This study demonstrates that successful roles are at least in part determined by shared expectations by different stakeholders. There is a need for more research looking at conceptualizations of advanced 
practice roles in different areas. There are few studies evident in the literature at this time. In addition, there is a paucity of studies reporting the facilitating factors and barriers to successful implementation of advanced practice roles. These conceptualizations, contextual barriers and facilitators need to be detailed if successful implementation of advanced nursing practice roles is the goal.

\subsubsection{Recommendations for Nursing Practice}

The major recommendation for nursing practice is aimed at those organizing or planning for advanced practice roles in their specialty areas. Stakeholders are clear that this is a complex process involving many stakeholders, not only in determining the actual role of the NP, but also being involved in the role development process. Stakeholders have conceptualizations that demonstrate the need to be implicated in shaping the process. They do not see this as a top down initiative; they see it as a process that requires their input, where they can contribute to the role's definition and implementation. Involving them in the process is necessary if the goal is to construct a role where the organization's goals are, at least in part, congruent with those of the current and future stakeholders. Using their expertise as well as their knowledge of the facilitating and impeding factors to implementation seems essential to the development of a successful role.

In addition, both the literature and this study demonstrate the importance of ensuring role clarity, a better understanding of role expectations and ensuring that nurses and other stakeholders understand the purpose and

the scope of advanced practice roles. Administrators are instrumental to preparing the organization for the successful implementation of advanced practice roles (Nevidjon, 2005: in Hamric et al, 2005). It is therefore 
essential that they are well informed of factors influencing this complex process and that they plan their interventions using stakeholders' conceptualizations. Furthermore, it is critical that they develop this advanced practice nursing role to meet patient centered, and health system needs rather than placing the emphasis on physician replacement or merely shifting role responsibilities from physicians to nurses. This role will challenge the current boundaries between these two professions; it is critical that those developing it understand its intended focus and outcomes and have a good understanding of the external legal context of which it is part.

\subsection{Conclusion}

The aim of this study was to identify the stakeholders' conceptualizations in the planning stage of the pediatric emergency nurse practitioner role. A descriptive exploratory method was used successfully to describe the stakeholders' conceptualizations of the NP role in the pediatric Emergency department, the role development process and the factors that favor and inhibit the development of this role. This study's findings demonstrate that stakeholders' conceptualizations are not based on rules and regulations, but rather on their clinical experience in the pediatric ED context.

Role development is a complex multi-phase process, which should be conceptualized as including a planning phase. The literature discusses the importance of using stakeholder conceptualizations in to minimize conflict in post-implementation phases of role development. Literature describing the planning phase of role development is scarce but essential to developing a successful role. Existing literature shows that a number of factors hinder or facilitate the implementation of advanced 
practice roles. The most important factors are lack of clarity (role ambiguity) and relationships among stakeholders. This study demonstrates that stakeholders' conceptualizations must be considered by administrators in order to develop a role based on the needs of the population with minimal impeding factors.

While the findings of this study cannot be generalized, it provides theoretical knowledge as well as concrete data which can be used in the planning phase of this advanced practice role. The findings also offer insight into facilitating and impeding factors affecting this clinical specialty. These two areas (the planning phase of role development of an advanced practice role and the factors favoring and impeding its implementation) are areas where little is a virtual void in available current literature. 


\section{REFERENCES}

Association des Infirmières et Infirmiers d'Urgence du Québec (AllUQ) (2000). Être infirmière d'urgence: un défi: document de recommandations sur les critères de formation de l'infirmière(ier) d'urgence. Quebec, Que.: Author.

American Heritage Dictionary of the English Language ( $4^{\text {th }}$ edition) (2000). Boston: Houghton Mifflin Company.

Blunt, E. (1998). Role and productivity of nurse practitioners in one urban emergency department. Journal of Emergency Nursing, 24(3), 234-239.

Brykczynski, K.A. (2005). Role development of the advanced practice nurse. In A. B. Hamric, J. A. Spross, \& C. M. Hanson, Advanced nursing practice - an integrative approach (pp.109-142) $\left(5^{\text {th }}\right.$ Ed.). St. Louis: Elsevier Saunders.

Buchanan, L., \& Powers, R. D. (1997). Establishing an NP staffed minor emergency area. The Nurse Practitioner, 22 (4), 175-187.

Bryant-Lukosius, D., DiCenso, A., Browne, G., Pinelli, J. (2004). Advanced practice nursing roles: development, implementation and evaluation. Journal of Advanced Nursing, 48(5), 519-529.

Canadian Nurses' Association. (2000). Advanced nursing practicea national framework. Ottawa, ON: Author. 
Chenitz, W. C. (1986). From Practice to Grounded Theory. Menlo Park, Ca.: Addison- Wesley Publishing Company.

Coffey, A., \& Atkinson, P. (1996). Making sense of qualitative data. Thousand Oaks: Sage.

Cole, F. L., \& Catalino, J. M. (1998). The acute care nurse practitioner in the emergency department setting. In M.R. Kleinpell, \& M.R. Piano, Practice Issues for the acute Care Nurse Practitioner (pp. 144-159). New York: Springer.

Cole, F. L., \& Ramirez, E. (1997). The emergency nurse practitioner: an educational model. Journal of Emergency Nursing 23(2), 112-115.

Cole, F. L., \& Ramirez, E. (1999). Evaluating an emergency nurse practitioner educational program for its relevance to the role. Journal of Emergency Nursing, 25(6), 547-550.

Cole, F. L., \& Ramirez, E. (2000). Activities and procedures performed by nurse practitioners in emergency care settings. Emergency Nurse 7(9), 26-30.

Conway, M. E. (1978). Theoretical approaches to the study of roles. In M. E. Hardy \& M. E. Conway, Role theory: perspectives for health professionals (pp.17-27). New York: Appleton-Century-Crofts.

Dowling, D., \& Dudley, W. N. (1995). Nurse practitioners: meeting the ED's needs. Nursing Management 26(1), 48C-48J. 
ENA (Emergency Nurses Association) (1999). Scope of practice for the nurse practitioner in the emergency care setting. Retrieved September 10, 2001, from www.ena.org.

ENA (Emergency Nurses Association) (2000). Position statement: advanced practice in emergency nursing. Retrieved September 10 , 2001, from www.ena.org.

ENA (Emergency Nurses Association) (2001). Standards of practice: nurse practitioners in emergency care. Retrieved September 10, 2001, from http://sonser4.nur.uth.tmc.edu/ecnps

Glaser, B. G. \& Strauss, A. L. (1967). The Discovery of Grounded Theory: Strategies for Qualitative Research. Chicago: Aldine Atherton.

Gouvernement du Québec. (1999a). Plan d'action; la situation dans les urgences en 1999: un défi majeur pour le réseau. Groupe d'experts en organisation clinique. Quebec: MSSS. Quebec.

Haddad, B. (1992). Report on the expanded role nurse project. Canadian Journal of Nursing Administration, 5(4), 10-17.

Hamric, A. B., Spross, J. A., \& Hanson, C. M. (1996). Advanced nursing practice: an integrative approach. Philadelphia: W. B. Saunders Company.

Hamric, A. B., Spross, J. A., \& Hanson, C. M. (2005). Advanced nursing practice: an integrative approach. St. Louis: Elsevier Saunders. 
Harahill, M., \& Eastes, L. (1999). Trauma nurse practitioner: the perfect job? Journal of Emergency Nursing, 25(4), 337-338.

Hardy, M. E., \& Conway, M. E. (1978). Role theory: perspectives for health professionals. New York: Appleton-Century-Crofts.

Hickey, J. V., Ouimette, R. M., \& Venegoni, S. L. (2000). Advanced practice nursing - changing roles and clinical applications. Philadelphia: Lippincott.

Hilbert, R. A. (1981). Toward an improved understanding of "role". Theory and Society, 10(2), 207-226.

Jones, M.L. (2003). Role development and effective practice in specialist and advanced practice roles in acute hospital settings: systematic review and meta-synthesis. Journal of Advanced Nursing, 49(2), 191-209.

Jones, S. (1996). An action research investigation into the feasibility of experienced registered sick children's nurses (RSCNs) becoming children's emergency nurse practitioners. Journal of Clinical Nursing, 5, 13-21.

Kemp, V. H. (1998). Providing care to children and their families in the emergency center. Journal of the Society of Pediatric Nurses, 3(4), 167-169.

Knafl, K. A. (1978). How nurse practitioner students construct their role. Nursing Outlook, 26(10), 650-653. 
Lincoln, Y.S. (1985). Organizational theory and inquiry: the paradigm revolution. Beverley Hills, Ca: Sage.

Lininger, R.A. (2004). Pediatric nurse practitioner sedation specialty role. Journal of Pediatric Health Care, 18(3), 158-160.

Miles, M.B., Huberman, A.M. (1994). Qualitative data analysis: An expanded sourcebook. Thousand Oaks,Ca: Sage.

Ordre des infirmières et infirmiers du Québec (OIIQ) (2001). La légalisation de la pratique de l'infirmière spécialisée et de l'infirmière praticienne. In La vision contemporaine de l'exercice infirmier au Québec (pp. 41-46). Montréal, Que.: Direction des services aux clientèles et des communications, OIIQ.

Paillé, P. (1994). L'analyse par théorisation ancrée. Cahiers de recherches sociologiques, 23, 147-181.

Patterson, C., \& Haddad, B. (1992). The advanced nurse practitioner: common attributes. Canadian Journal of Nursing Administration, 5(4), 18-22.

Patton, M.Q. (1990). Qualitative evaluations and research methods (2nd ed.). Newbury Park: Sage Publications.

Reveley, S. (1998). The role of the triage nurse practitioner in general medical practice: an analysis of the role. Journal of Advanced Nursing, 28(3), 584-591. 
Robertson, K. (1999). Trauma nursing: an advanced practice case study. The Canadian Nurse, 95(4), 18-22.

Rubin, S. (1988). The expanded role nurse: part 2: role implementation strategies. Canadian Journal of Nursing Administration 1(3), 12-15.

Sakr, M., Angus, J., Perrin, J., Nixon, C., Nicholl, J., \& Wardrope, J. (1999). Care of minor injuries by emergency nurse practitioners or junior doctors: a randomized controlled trial. The Lancet, 354, 13211326.

Sandelowski, M. (1986). The Problem of Rigor in Qualitative Research. Advances in Nursing Science, 8(3), 27-37.

Sanning Shea, S., \& Selfridge-Thomas, J. (1997). The ED nurse practitioner: pearls and pitfalls of role transition and development. Journal of Emergency Nursing, 23(3), 235-237.

Sica Bannert, J. (2000). Nurse practitioner offers ways to follow-up with positive laboratory results after patients leave. Journal of Emergency Nursing, 26(4), 294.

Silvestri, A., \& McDaniel-Yakscoe, $N$ (2001). A pediatric department follow-up system: Completing the cycle of care. Pediatric Emergency Care, 17(5), 392-395.

Silvestri, A \& McDaniel-Yakscoe, N (2005). Observation Medicine: The expanded Role of the Nurse Practitioner in a Pediatric Emergency Department Extended Care Unit. Nusing Forum, 21(3), 199-202. 
Strauss, A., \& Corbin, J., (1990). Basics of Qualitative Research: Grounded Theory Procedures and Techniques. Newbury Park, Ca: Sage Publications.

Strauss, A., \& Corbin, J., (1998). Basics of Qualitative Research: Techniques and Procedures for Developing Grounded Theory. Thousand Oaks, Ca: Sage Publications.

Tye, C. C., \& Ross, F., (1997). The emergency nurse practitioner role in major accident and emergency department: professional issues and the research agenda. Journal of Advanced Nursing, 26, 364-370.

Tye, C. C. (2000). Blurring boundaries: professional perspectives of the emergency nurse practitioner role in a major accident and emergency department. Journal of Advanced Nursing, 31(5), 10891096.

Van Der Horst, M. A. L., Patterson, C. A. (1993). General medicine expanded role nurse: role description. Canadian Journal of Nursing Administration, 6(3), 22-25.

Weick, K.E. (1985). Sources of order in the underorganized systems; themes in recent organizational theory. In Y.S. Lincoln, (ed.), Organizational theory and inquiry: the paradigm revolution (pp. 106136). Beverley Hills, Ca: Sage.

Woods, L. P. (1999). Implementing advanced practice: identifying the factors that facilitate and inhibit the process. Journal of Clinical Nursing, 7, 265-273. 
Zimmermann, P. G., Pierce, B. (1998). Nurse practitioners outside the fast track. Journal of Emergency Nursing, 24(5), 439-440. 


\section{APPENDIX A}

\section{Interview Guide}

Research and Clinical Descriptions the Role of Emergency Nurse Practitioners and Its Evolution in Other Settings

The literature emergency nurse practitioner roles; and some have even described certain difficulties they experienced when NPs integrated their new roles.

Tell me about what you would expect of a Nurse Practitioner in your ED to be doing.

What do you believe are important characteristics of an effective NP role in your ED?

In your opinion, what are emergency nurse practitioners in other EDs doing that you think would enhance patient care services in your ED?

What are your views of what the NP could be doing in this ED that would contribute to patient care services?

How do you expect this new role would change unit functioning, with regards to how nurses and physicians function now? 


\section{Role Development}

Emergency nurse practitioner role development is not well documented in the literature. How the decisions, about such development, are made and on what basis, remain unclear. This process likely implicates many, but the 'who' and the 'how' varies.

How do you see this role being developed? Who do you think should be involved in the development process?

What aspects of current ED practice would you see as appropriate for the emergency nurse practitioner to be doing in this hospital?

How do you see this role in terms of research and education?

What do you believe are important characteristics of an effective emergency nurse practitioner role in our hospital?

\section{The Context}

Each context is unique, with its strengths, limitations, and its unique perspective on issues.

Tell me about the ED context and how it might affect the process of integrating a Nurse Practitioner

In your opinion, what other types of contextual factors need to be considered with regards to the development of this role? 
What are the effects of these contextual factors on the role development process?

\section{Position Statements and Legal Aspects Which Govern the Clinical Context for NPs}

Legal aspects and various position statements have been published with the goal of documenting the laws which governs the clinical context for NPs in Québec, and establishing scope of practice and standards of care for NPs.

Can you tell me in what ways the laws and various positions statements have influenced your vision of this role and its limitations?

Are you aware of any published position statements on emergency nurse practitioners? If yes, in light of these, what are your views of the essence of this role and its purpose?

\section{Demographic Data}

Sex

Occupation

\# of years in your current position

\# of years in your profession

I have worked in an institution which employs emergency nurse practitioners:

YES $\square \quad$ FOR A PERIOD OF

NO 


\section{APPENDIX B}

\section{Request for Your Participation in a Research Project}

I am a student currently enrolled in the Faculty of Nursing at the Université de Montreal. The purpose of this letter is to request your participation in this qualitative study in your institution as part of my Master's program.

This study involves you as an employee of the hospital, as a nurse, physician or administrator who has knowledge of the ED that could be pertinent for the development of an emergency nurse practitioner role in this setting. I am especially interested in the conceptualizations you, as a stakeholder, hold of the emergency nurse practitioner role, if it were implemented in the future, in your institution. An understanding of this process would shed light on how roles are developed as well as important data for those involved in the development of this role in the future.

Your participation in this study is entirely voluntary. You are requested to participate in one audio taped interview for 60 minutes. This interview would take place in your office so as to minimize any inconvenience. You may be asked to answer other questions (briefly) at a later time if the need arises. The date and time of the interview will be fixed according to your availability. All data will be strictly confidential, with the audiotapes kept in a secure area. You may withdraw from the study at any time. Audiotapes will be destroyed after analysis is completed. Please contact me or my research director for any questions you may have regarding this study. 


\section{Title of the Study}

Stakeholders' Conceptualizations of the Nurse Practitioner Role in the pediatric Emergency department

\section{Duration of Data Collection}

May 1, 2004 - November 31, 2004

\section{Aim of the Study}

This study will advance our theoretical understanding of the social factors that favour and impede the development of the emergency nurse practitioner role. The aim of the study is to identify the factors which favour and impede role development, the stakeholders' conceptualizations in the planning stage of the emergency nurse practitioner role and how these conceptualizations are related to their expectations of the pediatric emergency nurse practitioner.

\section{Method}

A qualitative method, largely influenced by grounded theory methodology has been selected to study the emerging phenomenon of role development of the Nurse Practitioner in the pediatric ED. Stakeholders have a conceptualization of what this role should be, based on the needs they see, and their beliefs of what this role would bring to the department and to the institution. Within their own contexts, they have their view of how this role should be developed. Because little is known about this emerging phenomenon, it is appropriate to use 
descriptive qualitative design. Members of hospital staff (participants) whose participation will be requested include:

- Senior ED staff nurse(s)

- ED physician(s)

- ED Acting Head Nurse

- ED Clinical Nurse Specialist

- Council of Nurses representative(s)

- Director of Nursing

- Director of Professional Services

- Chief of the Council of Physicians, Dentists and Pharmacists

Other sources of data will also be studied. The study will review related documents such as scope of practice documents, role statements, and position statements pertinent to the role of nurse practitioner. Field notes and observation notes will also be kept.

\section{Risk for Participants and Control Measures}

We do not anticipate any negative effects for participants. All recorded materials will be stored in a locked area and destroyed after the study is finished. Participants may choose to withdraw from the study at any moment.

\section{Scientific Merit/Social Value}

The knowledge gained through this study will serve to guide the development of this new role. It will shed knowledge on how this role will be developed. It will shed light on how this advanced practice role is 
viewed in this context. It will contribute to nursing knowledge on this advanced practice role.

Student Researcher: Louise Murray, Master's student

Faculté des Sciences infirmières

Université de Montréal

Study Supervisor: Mary Reidy, Professor

Faculté des Sciences infirmières

Université de Montréal

514-343- 7088

Study Co-Supervisor: Franco Carnevale, Coordinator, Critical Care Services Montreal Children's Hospital, MUHC

514-412-4400 \#22449

\section{Consent Form for Participants}

\section{Title of the Study}

The Stakeholders' Conceptualizations of the Nurse Practitioner Role in the Pediatric Emergency Department

\section{Date/duration of Data Collection}

May 1, 2004 - November 31, 2004 


\section{Title of the Study}

The Stakeholders' Conceptualizations of the Nurse Practitioner Role in the pediatric Emergency department

\section{Date/Duration of Data Collection}

I understand the above mentioned conditions and I have received satisfactory answers to my questions. I accept to participate in this study, and I understand that I will be participating in a 60 minute audio taped interview with Louise Murray in my office at an agreed time.

I also agree to the publication of the data collected for this study as long as confidentiality if maintained.

NAME:

SIGNATURE:

DATE:

This consent form was read and signed in my presence. As stated I will maintain this participant's confidentiality.

STUDENT RESEARCHER:

SIGNATURE:

DATE: 


\section{APPENDIX C}

\section{Data Category Analyses: Divergence and Convergence of Categories Among Participants}

Table II - Conceptualizations of NP role

\begin{tabular}{|c|c|c|c|c|c|c|c|c|c|c|c|}
\hline \multirow[t]{2}{*}{ Conceptualizations of NP Role } & \multicolumn{4}{|c|}{ Nurse } & \multicolumn{4}{|c|}{ Physician } & \multicolumn{3}{|c|}{ Administrator } \\
\hline & 1 & 2 & 3 & 4 & 1 & 2 & 3 & 4 & 1 & 2 & 3 \\
\hline Work as part of a team & & & $x$ & $x$ & $x$ & $x$ & & & & & \\
\hline Not be involved in critical care/consults: & & $x$ & $\mathrm{x}$ & & $x$ & $\mathbf{x}$ & & $\mathbf{x}$ & & & \\
\hline $\begin{array}{l}\text { Perform advanced procedures/deliver } \\
\text { complex care using protocols }\end{array}$ & $x$ & & $x$ & $x$ & $x$ & $\mathbf{x}$ & & & & & \\
\hline $\begin{array}{l}\text { Initiate treatment for physician after } \\
\text { triage for selected populations using } \\
\text { protocols }\end{array}$ & & & & & & $x$ & $x$ & $x$ & & & \\
\hline Limit NP to selected populations & $x$ & $\mathbf{x}$ & $\mathrm{x}$ & & $\mathbf{x}$ & & $\mathbf{x}$ & $x$ & & & \\
\hline $\begin{array}{l}\text { Largely clinical role for selected fast } \\
\text { track patients with clear diagnosis }\end{array}$ & $x$ & $x$ & $x$ & & $x$ & & $x$ & $x$ & $x$ & $x$ & $x$ \\
\hline $\begin{array}{l}\text { Reflect nurse/physician hybrid } \\
\text { responsibilities }\end{array}$ & $\mathbf{x}$ & $\mathbf{x}$ & $x$ & $x$ & $x$ & & $x$ & $\mathbf{x}$ & $x$ & & \\
\hline $\begin{array}{l}\text { Teach/mentor nurses, trainees and } \\
\text { patients }\end{array}$ & $x$ & & $x$ & $x$ & $x$ & $x$ & $\mathbf{x}$ & $x$ & & & \\
\hline Limit administrative role & & & & & $x$ & $x$ & & & & & \\
\hline Clarify NP responsibilities & $x$ & $x$ & $x$ & $\mathrm{x}$ & $x$ & & $x$ & $\mathrm{x}$ & & $\mathbf{x}$ & \\
\hline $\begin{array}{l}\text { Determine independence, autonomy } \\
\text { and ultimate legal responsibility for } \\
\text { patient }\end{array}$ & $x$ & $x$ & & & $x$ & $\mathrm{x}$ & $x$ & $x$ & $x$ & & \\
\hline Limit research responsibilities & $\mathbf{x}$ & $x$ & $x$ & & $x$ & $x$ & $x$ & & & & \\
\hline Extend nursing role beginning at triage & & $x$ & $x$ & $x$ & $x$ & & $x$ & & & $x$ & \\
\hline $\begin{array}{l}\text { Bridge gaps between nursing and } \\
\text { physician roles }\end{array}$ & $x$ & $x$ & $x$ & & & $x$ & & & & & \\
\hline $\begin{array}{l}\text { Provide follow-up for specific } \\
\text { populations }\end{array}$ & & & & $x$ & $x$ & & $x$ & $x$ & & & \\
\hline
\end{tabular}


Table III - Conceptualizations of role development process

\begin{tabular}{|c|c|c|c|c|c|c|c|c|c|c|c|}
\hline \multirow{2}{*}{$\begin{array}{l}\text { Conceptions and Expectations of } \\
\text { Role Development Process }\end{array}$} & \multicolumn{4}{|c|}{ Nurse } & \multicolumn{4}{|c|}{ Physician } & \multicolumn{3}{|c|}{ Administrator } \\
\hline & 1 & 2 & 3 & 4 & 1 & 2 & 3 & 4 & 1 & 2 & 3 \\
\hline Attend to group process & $x$ & $x$ & $x$ & $\mathbf{x}$ & $x$ & $\mathbf{x}$ & $x$ & $\mathbf{x}$ & $x$ & & $x$ \\
\hline $\begin{array}{l}\text { Build new role on competencies/consider } \\
\text { needs, limitations }\end{array}$ & $x$ & $x$ & $x$ & & $x$ & $x$ & & & & & \\
\hline Identify educational requirements & $\bar{x}$ & & $\bar{x}$ & & $\bar{x}$ & $\bar{x}$ & & & & & \\
\hline $\begin{array}{l}\text { Use a recognized process of role } \\
\text { development/learn from others }\end{array}$ & & $x$ & $x$ & & $x$ & $x$ & $x$ & $x$ & & & \\
\hline $\begin{array}{l}\text { Enlist support from ED stakeholders } \\
\text { and administrators }\end{array}$ & $x$ & & & & $x$ & $x$ & $x$ & $x$ & $x$ & $x$ & $x$ \\
\hline $\begin{array}{l}\text { View NP role as a new role, redefine } \\
\text { other nursing roles }\end{array}$ & $\mathbf{x}$ & $\mathbf{x}$ & $\mathbf{x}$ & $x$ & & $x$ & & $x$ & $\mathbf{x}$ & & \\
\hline $\begin{array}{l}\text { Consider special challenges for first } \\
\text { candidates }\end{array}$ & & & $x$ & & $x$ & $x$ & & & $x$ & & \\
\hline $\begin{array}{l}\text { Determine role expectations in this } \\
\text { context/limit input from governing bodies }\end{array}$ & $x$ & $x$ & $x$ & $x$ & & $x$ & $x$ & $x$ & $x$ & & $x$ \\
\hline Consider evolution of role over time & $x$ & & $x$ & & & $x$ & $x$ & $\mathrm{x}$ & $\mathbf{x}$ & & \\
\hline $\begin{array}{l}\text { Recognize this role will change current } \\
\text { nurse/physician dynamics }\end{array}$ & $x$ & $x$ & $x$ & $x$ & & $x$ & & $x$ & $x$ & $x$ & \\
\hline Consider impact of new role on nurses & & $x$ & $x$ & $\mathrm{x}$ & & $x$ & & & & & \\
\hline $\begin{array}{l}\text { Consider impact of new role on } \\
\text { physicians }\end{array}$ & $\mathbf{x}$ & $x$ & $x$ & & $\mathbf{x}$ & & $x$ & & & & \\
\hline $\begin{array}{l}\text { Ensure candidates are autonomous, } \\
\text { clinical experts with strong interpersonal } \\
\text { skills }\end{array}$ & $x$ & & $x$ & $x$ & $x$ & $x$ & $x$ & $x$ & & & $x$ \\
\hline Anticipate potential benefits of NP role & $x$ & $x$ & $\mathrm{x}$ & $x$ & $x$ & $x$ & $x$ & $x$ & & & \\
\hline
\end{tabular}


Table IV - ER Context

\begin{tabular}{|c|c|c|c|c|c|c|c|c|c|c|c|}
\hline \multirow[t]{2}{*}{ ER Context } & \multicolumn{4}{|c|}{ Nurse } & \multicolumn{4}{|c|}{ Physician } & \multicolumn{3}{|c|}{ Administrator } \\
\hline & 1 & 2 & 3 & 4 & 1 & 2 & 3 & 4 & 1 & 2 & 3 \\
\hline $\begin{array}{l}\text { Consider the NP role an addition to } \\
\text { current human resources }\end{array}$ & $x$ & $x$ & $x$ & & $x$ & & $x$ & & $\mathrm{x}$ & $x$ & $x$ \\
\hline $\begin{array}{l}\text { Consider unpredictable environment } \\
\text { with high patient volumes and rapid } \\
\text { turnover }\end{array}$ & $x$ & & $x$ & $x$ & $x$ & $x$ & $x$ & & & & \\
\hline $\begin{array}{l}\text { Consider factors influencing longevity } \\
\text { of Emergency nurse practitioner role }\end{array}$ & & & & & & & $x$ & $x$ & & $x$ & \\
\hline $\begin{array}{l}\text { Consider the impact of large numbers } \\
\text { of staff/turnover }\end{array}$ & $x$ & & & $x$ & & & $x$ & $x$ & & & \\
\hline $\begin{array}{l}\text { Consider parents' reaction to change in } \\
\text { model for delivery of care }\end{array}$ & $x$ & & $x$ & & $x$ & & $x$ & & $x$ & $x$ & $x$ \\
\hline Consider financial resources & $\mathrm{x}$ & & $x$ & & $x$ & & & & $x$ & & $x$ \\
\hline $\begin{array}{l}\text { Consider MCH history in NP } \\
\text { development }\end{array}$ & & & $x$ & & & $x$ & & & & & $x$ \\
\hline Consider potential barriers & & $x$ & & & & & & & $x$ & $x$ & $x$ \\
\hline Consider facilitating factors & $x$ & & $x$ & & $x$ & & & & & & $x$ \\
\hline $\begin{array}{l}\text { Consider OII, College des médecins } \\
\text { and other governing bodies }\end{array}$ & & & & & & & & & & $x$ & $x$ \\
\hline
\end{tabular}

Table V - Legal context/Position statements

\begin{tabular}{|l|c|c|c|c|c|c|c|c|c|c|c|c|}
\hline \multicolumn{1}{|c|}{ Legal context/Position Statements } & \multicolumn{3}{|c|}{ Nurse } & \multicolumn{3}{c|}{ Physician } & \multicolumn{3}{c|}{ Administrator } \\
\cline { 2 - 12 } & & 1 & 2 & 3 & 4 & 1 & 2 & 3 & 4 & 1 & 2 & 3 \\
\hline $\begin{array}{l}\text { Determine accountability and } \\
\text { responsibilities in an unciear legal } \\
\text { context }\end{array}$ & $\mathrm{x}$ & & $\mathrm{x}$ & & $\mathrm{x}$ & $\mathrm{x}$ & $\mathrm{x}$ & & & & \\
\hline $\begin{array}{l}\text { Consider Quebec's evolving legal } \\
\text { context }\end{array}$ & & & $\mathrm{x}$ & & $\mathrm{x}$ & & $\mathrm{x}$ & & & & $\mathrm{x}$ \\
\hline Unfamiliar with position statements & & $\mathrm{x}$ & $\mathrm{x}$ & $\mathrm{x}$ & $\mathrm{x}$ & & & $\mathrm{x}$ & & & \\
\hline
\end{tabular}


